CHANGES IN THE RELATIVE WEIGHTS OF THE VARIOUS PARTS, SYSTEMS AND ORGANS OF YOUNG ALBINO RATS UNDERFED FOR VARIOUS PERIODS

BY

CHESTER A. STEWART

A thesis submitted to the faculty of the graduate school of the University of Minnesota in partial fullfilment of the requirements for the degree of Doctor of Philosophy 
ACTHOR's AHSTRACT OF THIS PAPEB ISSDEF BY THE BLBLIOGRAPHC SERVICE, YEBRUARY 2
Reprinted from The Jounsal of Experimental Zoölogr, Vol. 25, No. 2, April, 1918

\section{CHANGES IN THE RELATIVE WEIGHTS OF THE VARI- OUS PARTS, SYSTEMS AND ORGANS OF YOUNG ALBINO RATS UNDERFED FOR VARIOUS PERIODS}

\section{CHESTER A. STEWART}

Institute of Anatomy, University of Minnesota, Minneapolis ONE FIGURE AND FOUR TABLES

\section{CONTENTS}

Material and methods....

Ratio of tail length to body length................................. 318

Head........................................................ 319

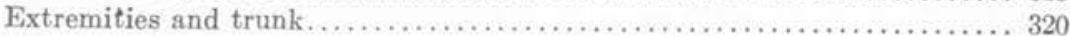

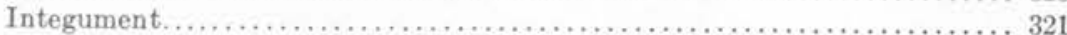

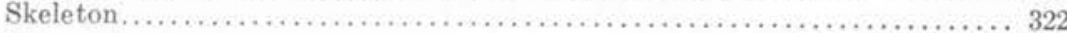

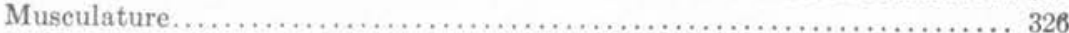

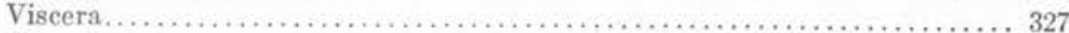

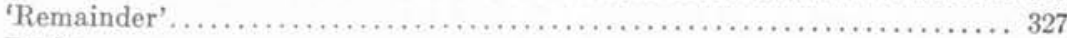

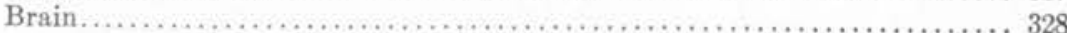

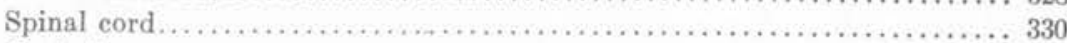

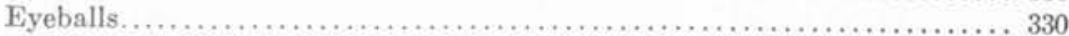

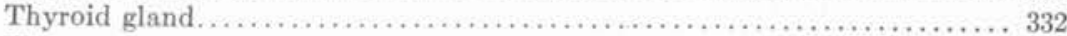

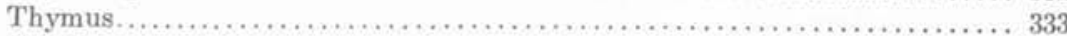

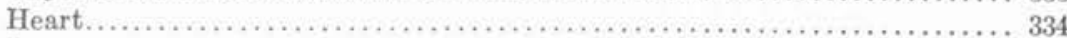

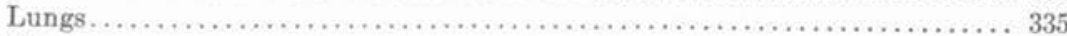

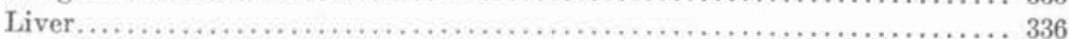

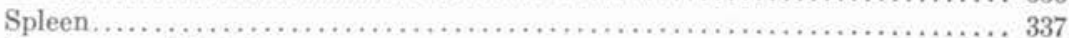

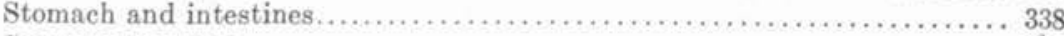

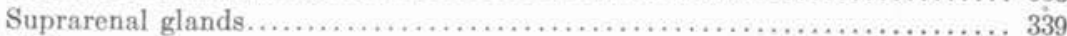

Kidneys.................................................. 340

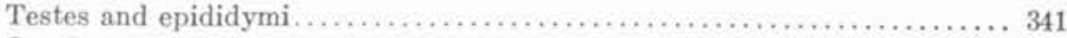

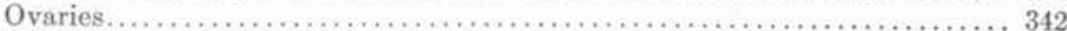

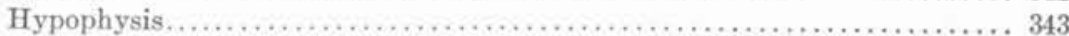

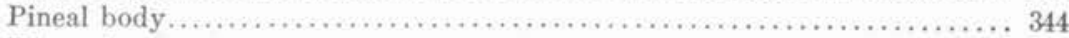

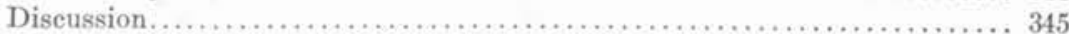

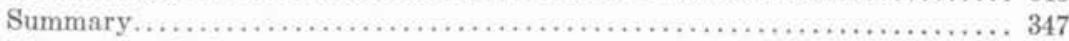

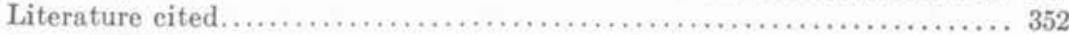

It has recently been shown that although growth in body weight in the young rat may be completely suppressed by underfeeding 301

THE JOURNAL, OF EXPERIMENTAL, zOÖLOGY, VOL. 25, No. 2 XPRI., 1918 
- for considerable periods, nevertheless, certain organs and parts of the body having a very strong growth tendency continue to increase in weight, other organs and parts with a weaker growth capacity remain nearly unchanged, while still other parts suffer a loss in weight (Jackson '15 b and Stewart '16). These changes were observed chiefly in rats whose underfeeding began at the age of three weeks and terminated at the age of ten or twelve weeks. Very few observations have been recorded, however, concerning such changes which may occur either in younger animals subjected to inanition for various periods, or in animals underfed for much longer periods. An investigation was therefore undertaken in order to determine these changes. The work was done in the Institute of Anatomy of the University of Minnesota, under the supervision of Dr. C. M. Jackson, to whom I am indebted for valuable aid and direction.

\section{MATERIAL AND METHODS}

For the present investigation eighty-nine albino rats (Mus norvegicus albinus) were used (table 1), all of which were autopsied at the close of the experiment. They included thirty-four controls and fifty-five test rats.

From the litters used, the controls were selected at the beginning of the experiment, the sex being determined according to the method of Jackson ('12). Seven (4 M, 3 F) of the controls were killed and autopsied when they had reached (on full feeding) an approximate average net body weight of 10 grams, four ( . M, $1 . \mathrm{F})$ at 13 grams, fourteen ( $7 \mathrm{M}, 7 \mathrm{~F}$ ) at 15 grams, one (M) at 27 grams, one (F) at 40 grams, four ( $2 \mathrm{M}, 2 \mathrm{~F}$ ) at 50 grams, and three $(2 \mathrm{M}, 1 \mathrm{~F})$ at 70 grams. Whenever possible, the controls were selected from the same litters as the test rats. In some instances, however, this was not possible, especially in the case of the controls for the rats underfed for very long periods.

The majority of the test rats were starved for intermittent periods starting a short time ( 24 to 48 hours) after birth, and were killed (by chloroform) and autopsied at the age of three weeks (17 rats; $9 \mathrm{M}, 8 \mathrm{~F}$ ), six weeks ( 9 rats; $6 \mathrm{M}, 3 \mathrm{~F}$ ), and ten weeks 
TABLE 1

Average and range of gross and net body weight, body length, tail ratio, and weights of the head, trunk, extremities, skeleton, musculature Test rats in first six groups were underfed from birth; last six groups from age of three weeks

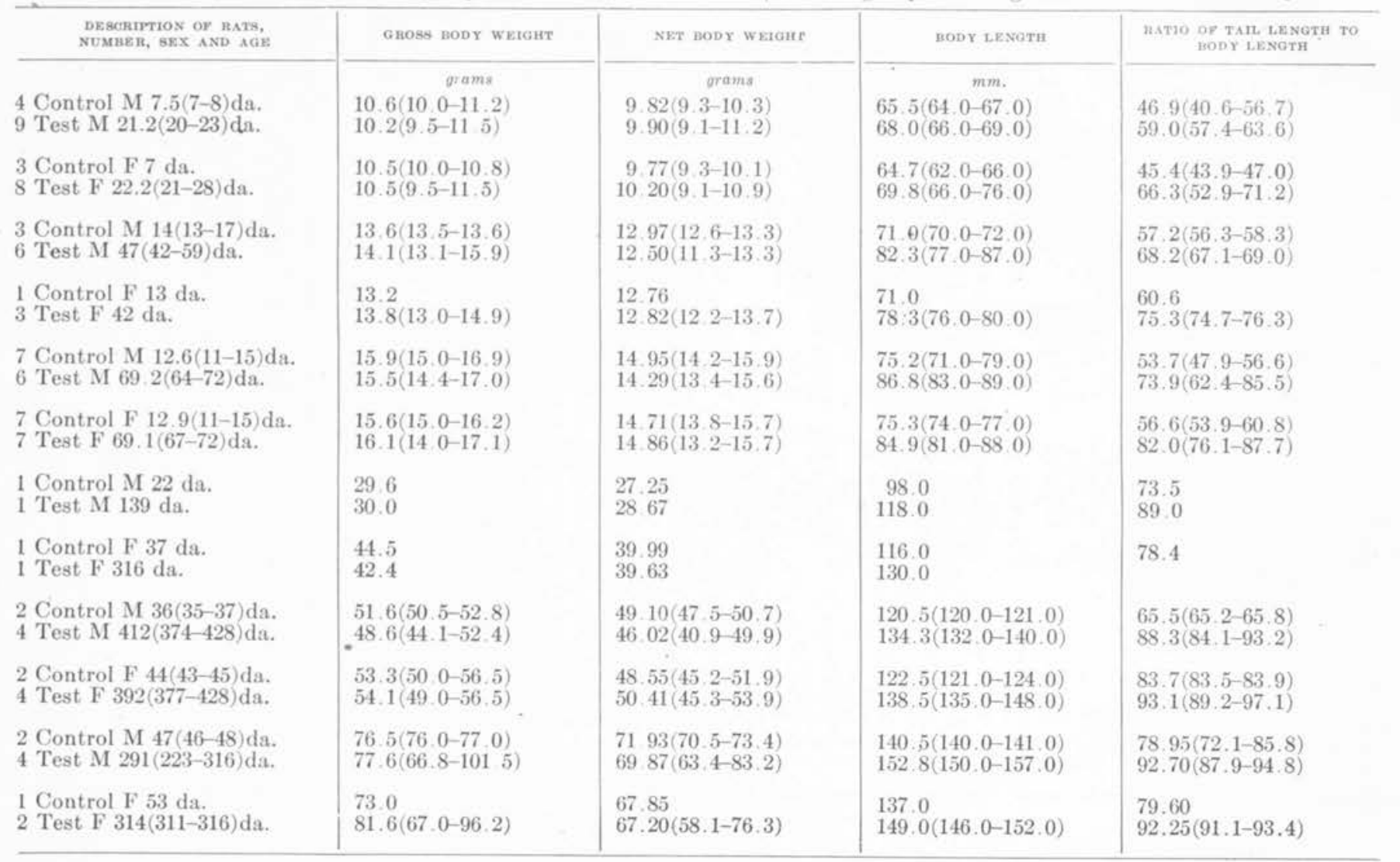


TABLE 1-Continued

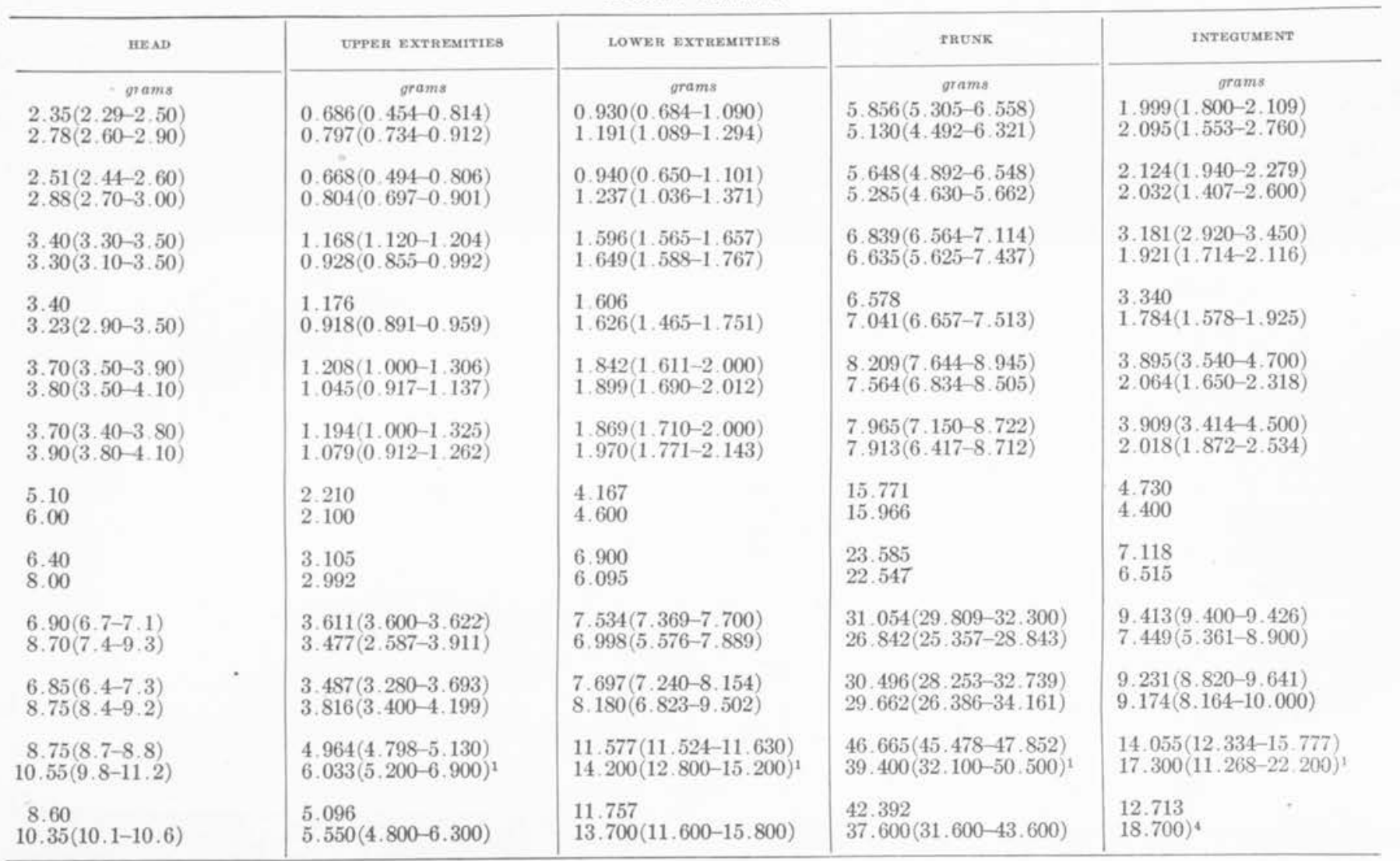




\begin{tabular}{|c|c|c|c|c|c|}
\hline LIOAMENTOUS SKELETON & $\begin{array}{l}\text { MOIST CARTLAGINODB } \\
\text { BKELLTTON }\end{array}$ & $\begin{array}{c}\text { DRY CARTILAGINOUS } \\
\text { SEELETON }\end{array}$ & MUSCULATURE & VIACERAI. GROLT & REMAINDER \\
\hline $\begin{array}{c}\text { grams } \\
1.636(1.393-1.799) \\
1.915(1.767-2.092)\end{array}$ & $\begin{array}{c}\text { grams } \\
0.715(0.481-0.959)^{\mathrm{r}} \\
1.610(1.398-1.887)^{\prime}\end{array}$ & $\begin{array}{c}\text { grams } \\
0.145(0.118-0.184)^{1} \\
0.359(0.290-0.451)^{2}\end{array}$ & $\begin{array}{c}\text { grams } \\
2.244(1.590-2.473) \\
2.442(2.197-2.986)\end{array}$ & $\begin{array}{c}\text { grams } \\
1.977(1.891-2.153) \\
2.501(2.271-2.719)\end{array}$ & $\begin{array}{l}\text { grams } \\
1.964(1.664-2.686) \\
1.076(0.534-2.027)^{8}\end{array}$ \\
\hline $\begin{array}{l}1.598(1.509-1.700) \\
1.923(1.610-2.256)\end{array}$ & $\begin{array}{l}0.856(0.543-1.168)^{3} \\
1.440(1.216-1.897)\end{array}$ & $\begin{array}{l}0.136^{4} \\
0.389(0.328-0.492)^{2}\end{array}$ & $\begin{array}{l}2.356(2.020-2.745) \\
2.530(1.640-2.890)\end{array}$ & $\begin{array}{l}2.002(1.896-2.135) \\
2.606(2.322-2.982)\end{array}$ & $\begin{array}{l}1.683(1.371-2.137) \\
1.109(0.583-1.554)\end{array}$ \\
\hline $\begin{array}{l}2.302(2.225-2.394) \\
2.686(2.536-2.867)\end{array}$ & $\begin{array}{l}1.699(1.519-1.865) \\
2.331(1.891-2.485)\end{array}$ & $\begin{array}{l}0.329(0.289-0.359) \\
0.554(0.483-0.753)\end{array}$ & $\begin{array}{l}\text { 3. } 053(2.953-3.119) \\
3.338(2.979-3.608)\end{array}$ & $\begin{array}{l}2.729(2.568-2.956) \\
3.512(3.181-3.905)\end{array}$ & $\begin{array}{l}1.705(1.184-2.129) \\
1.104(0.000-2.038)\end{array}$ \\
\hline $\begin{array}{l}2.297 \\
2.599(2.386-2.715)\end{array}$ & $\begin{array}{l}1.815 \\
2.350(2.308-2.418)\end{array}$ & 0.342 & $\begin{array}{l}3.190 \\
3.659(3.510-3.860)\end{array}$ & $\begin{array}{l}2.787 \\
3.563(3.400-3.745)\end{array}$ & $\begin{array}{l}1.146 \\
1.213(0.622-1.695)\end{array}$ \\
\hline $\begin{array}{l}2.372(2.130-2.714) \\
2.937(2.796-3.153)\end{array}$ & $\begin{array}{l}1.667(1.399-2.088)^{6} \\
2.568(2.121-2.737)^{6}\end{array}$ & $\begin{array}{l}0.376(0.336-0.423)^{1} \\
0.767(0.662-0 \\
0.856)^{5}\end{array}$ & $\begin{array}{l}3.840(3.609-4.060)^{5} \\
3.966(3.368-4.467)^{5}\end{array}$ & $\begin{array}{l}2.935(2.775-3.042) \\
3.840(3.425-4.209)\end{array}$ & $\begin{array}{l}1.877(1.686-2.131)^{5} \\
1.486(1.028-2.088)^{6}\end{array}$ \\
\hline $\begin{array}{l}2.341(2.204-2.561)^{5} \\
2.894(2.700-3.013)\end{array}$ & $\begin{array}{l}1.528(1.294-2.006)^{7} \\
2.386(1.948-2.847)\end{array}$ & $\begin{array}{l}0.372(0.350-0.390)^{7} \\
0.731(0.683-0.856)\end{array}$ & $\begin{array}{l}3.863(3.488-5.126)^{5} \\
4.475(3.660-5.227)\end{array}$ & $\begin{array}{l}2.935(2.758-3.168) \\
4.204(3.768-5.065)\end{array}$ & $\begin{array}{l}\text { 1. } 694(0.105-2.564)^{5} \\
1.271(0.855-1.703)\end{array}$ \\
\hline $\begin{array}{l}4.305 \\
5.400\end{array}$ & $\begin{array}{l}3.587 \\
4.300\end{array}$ & 2.079 & $\begin{array}{l}8.175 \\
8.500\end{array}$ & $\begin{array}{l}5.453 \\
5.388\end{array}$ & $\begin{array}{l}4.585 \\
4.978\end{array}$ \\
\hline $\begin{array}{l}5.844 \\
8.838\end{array}$ & 7.957 & 3.081 & $\begin{array}{l}14.448 \\
12.393\end{array}$ & $\begin{array}{l}7.448 \\
7.668\end{array}$ & $\begin{array}{l}5.132 \\
4.220\end{array}$ \\
\hline $\begin{array}{l}6.785(6.620-6.951) \\
8.151(7.558-8.796)\end{array}$ & $\begin{array}{l}5.572(5.411-5.733) \\
7.209(6.403-8.341)\end{array}$ & $\begin{array}{l}1.603(1.336-1.870) \\
3.523(2.897-4.035)\end{array}$ & $\begin{array}{l}16.650(16.320-16.980) \\
16.377(11.472-18.821)\end{array}$ & $\begin{array}{l}8.605(8.298-8.912) \\
8.893(7.934-11.283)\end{array}$ & $\begin{array}{l}7.651(5.900-9.402) \\
5.146(4.074-5.734)\end{array}$ \\
\hline $\begin{array}{l}6.207(6.066-6.347) \\
8.963(7.930-10.111)\end{array}$ & $\begin{array}{l}5.193^{4} \\
7.774(7.055-8.813)^{1}\end{array}$ & $3.942(3.340-4.415)$ & $\begin{array}{l}16.447(15.684-17.209) \\
18.110(13.355-21.076)\end{array}$ & $\begin{array}{l}9.646(8.935-10.356) \\
9.537(7.026-13.744)\end{array}$ & $\begin{array}{l}7.000(5.668-8.333) \\
4.626(3.466-5.894)\end{array}$ \\
\hline $\begin{array}{c}8.457(7.903-9.011) \\
12.500(11.300-13.800)^{\prime}\end{array}$ & $\begin{array}{l}7.197(6.281-8.104) \\
9.030(8.800-9.300)^{1}\end{array}$ & $\begin{array}{l}2.503(2.229-2.776) \\
4.273(3.738-4.890)\end{array}$ & $\begin{array}{l}28.082(26.474-29.690) \\
33.700(30.000-37.400)^{3}\end{array}$ & $\begin{array}{l}13.680(13.025-14.336) \\
11.186(10.733-11.639)^{3}\end{array}$ & $\begin{array}{l}7.662(5.129-10.196) \\
6.300^{4}\end{array}$ \\
\hline $\begin{array}{l}8.202 \\
11.550(11.100-12.000)\end{array}$ & $\begin{array}{l}7.232 \\
9.400(9.100-9.700)\end{array}$ & $3.856(3.692-4.020)$ & $\begin{array}{l}26.221 \\
35.300^{4}\end{array}$ & $\begin{array}{l}10.254 \\
10.698^{4}\end{array}$ & $\begin{array}{r}10.455 \\
0.000\end{array}$ \\
\hline
\end{tabular}


(13 rats; $6 \mathrm{M}, 7 \mathrm{~F}$ ), the average net body weight at each age being approximately 10,13 and 15 grams respectively.

In addition sixteen rats, starting at three weeks of age, were underfed for much longer periods (to 139 to 412 days of age; see table 1). They were then killed and autopsied. For one litter of the group fasting for a long period (M 29), the underfeeding started at the age of five weeks. Four rats of litters S 26 and M 29 (one male and one female of each litter), and one male of litter St 44 were accidentally asphyxiated by illuminating gas. These rats are all included in the two groups of test rats weighing approximately 70 grams. The two asphyxiated individuals of litter M 29 had been refed about thirty-six hours, which has resulted chiefly' in a great increase in the contents of the.alimentary canal.

In general the plan was to kill the test rats at the same body weight as the corresponding controls, but this was not always possible. Nevertheless, the average body weight of the different groups of test rats differs only slightly from that for the corresponding controls, as is shown in table 1 . In comparing the data from the test rats with those from the controls throughout the paper, this difference has generally been disregarded, although strictly speaking, there should be a slight correction in every case for differences in body weight. Such a correction should be based upon the net body weight (excluding content of stomach and intestines), rather than upon the gross body weight, however. As the differences in body weight are in all cases small, it seems justified to ignore them in making comparisons.

The control rats remained constantly with the mother throughout the nursing period (three weeks). After this time they were fed an abundant diet of whole wheat (Graham) bread soaked in whole milk. Water was also supplied.

The test rats (in the experiments upon very young animals) were removed from the mother at frequent intervals for periods of usually 15 to 24 hours (occasionally longer, the maximum being 43 hours), and were permitted to nurse during the intervening time. For convenience, these test rats are frequently referred to throughout this paper as the rats fasting from birth 
for various periods. The total number of hours that the test rats of a litter were separated from the mother during the first three weeks (504 hours) after birth averaged 260 hours (213 to 285 hours) or more than half of the total period. Brüning ('14) was able to isolate young rats from the mother for only about one-fourth of the total nursing period.

In most instances when young fasting rats were returned to the nest, the mother would immediately take care of them. Occasionally, however, after being disturbed, the mother would abandon her litter entirely. In these eases it was often possible to save the young rats by putting them to nurse with other mothers whose young were fasting at that time. By continually putting young rats of different litters in the nest, it was found possible to keep one female nursing for twelve weeks.

The age of weaning for the albino rat is usually given as three weeks. However, Donaldson ('15) ('The Rat,' p. 19) states that the young, if permitted, will continue to depend partly on the mother for some days longer. One of my litters was observed to continue nursing until six weeks of age.

When three weeks old, the test rats underfed from birth, and also those used in the experiments starting at three weeks, were placed on the bread and milk diet, receiving only a limited and carefully measured quantity daily. As was observed by Jackson ('15 b) and Stewart ('16), the young rats in the present experiments were kept at maintenance for a considerable period upon a gradually diminishing ration. Thus for one litter (St 96) during 30 days underfeeding the daily amount of food required for maintenance of body weight at approximately 14.5 grams decreased from an average of 3.87 grams to 2.97 grams per rat. Later, however, the maintenance ration apparently becomes more nearly constant. For example, in the case of another litter (St 46) underfed for a very long period the total daily weight of food consumed by 5 rats from the 131st to the 180 th day of the experiment was constantly 33 grams. The average body weight of these rats during this period remained unchanged ( $47.6 \mathrm{grams}$.)

- Stewart ('16) for one litter found no decrease in the maintenance ration from the 60 th to the 120 th day of the experiment. 
The decrease in the maintenance ration noted in the young stunted rats is perhaps associated with the decrease in the intensity of metabolism which normally oceurs with advancing age. Jackson (' $15 \mathrm{~b}$ ) suggests that during maintenance in young animals the amount of living protoplasm may be actually reduced, being replaced by water absorption, or that the food-intake may be more economically utilized under these conditions. He also mentions the decrease in body temperature as a possible factor. This problem is apparently of sufficient interest and importance to warrant a more exact and thorough investigation from the physiological point of view.

Since it was found very difficult to hold the test rats strictly at constant body weight and keep them alive for very long periods, a slight increase in body weight was usually permitted. Aron ('11), Jackson ('15 b) and Stewart ('16) similarly found it increasingly difficult to hold animals at constant body weight as the experiment progressed.

Separate weight records were kept for each rat, the individuals being identified by staining the integument with an alcoholic solution of picric acid. The identification marks had to be renewed morning and evening on the very young rats, but after the appearance of hains the stains were very permanent. The young test rats were weighed daily immediately before feeding. whereas the controls, and also the test rats underfed for very long periods, were weighed at gradually increasing intervals as they grew older (about once in two weeks when about three months of age).

The cages used, and also the warm room in which the test rats were kept while fasting, have been described by Stewart ('16).

The autopsy technique employed by Jackson and Lowrey ('12) and Jackson (13) was used with but few modifications. The various organs and parts were placed in a moist chamber when removed from the animal, and were weighed in a closed container on balances accurate to one-tenth milligram (0.0001 gram).

The data collected for the controls in this work were carefully compared with the published records of Jackson and Lowrey ('12), Jackson ('13 and '15), Hatai ('13 and '14), King ('15), and 
with the Wistar norm tables of Donaldson (15). By this means it was possible to detect any marked variations from the normal in my control rats. For purposes of convegient comparison, the weights of organs from the Wistar tables for normal rats of body length corresponding to my controls have been inserted in table 2. In general, it will be noted that both the body weight and the corresponding organ weights are slightly higher in my controls than in the Wistar tables. If the comparison were based upon body weight rather than body length, there would usually be much closer agreement. While body length is a satisfactory basis for comparison between my controls and the Wistar data, it cannot be used in the case of the test rats, for as will appear later, the body length in underfed rats continues to increase even when the body weight is held constant. Body weight therefore was selected as a basis for comparison between my controls and test rats, since it can easily be held constant, which is not true for the body length.

In the present paper, for the most part only average data are published. However, a copy of the original individual observations will be deposited in The Wistar Institute of Anatomy and Biology, Philadelphia, where they may be consulted by those interested.

The normal variability of the various organs makes it necessary in some cases to exercise considerable care in drawing conclusions from the relatively limited number of observations. Nevertheless, the data appear sufficient to establish fairly accurately some of the more obvious and important changes due to the experiment.

An abstract of that part of the present investigation dealing with the underfeeding of the rats from birth to three, six and ten weeks of age was published in the Proceedings of the American Association of Anatomists, New York meeting, December, 1916 (Stewart, '17). 
TABLE 2

Average (and range) of weight of the organs, with data from the Wistar tables (Donaldson, '15) for rats of body length corresponding to my controls. (In case of the thymus age is the basis of comparison)

Test rats in the first six groups were underfed from birth; last six groups from age of three weeks

\begin{tabular}{|c|c|c|c|c|c|}
\hline $\begin{array}{l}\text { DESCRIPTION OF RATS, NUMAaER, } \\
\text { BEX AND AGE }\end{array}$ & BODY LENCTH & GROSA BODY WEIOHT & NET BODY WEIGHT & BRAIN & BPINAL CORD \\
\hline & $m m$. & arams & grams & grams & grams \\
\hline 4 Control M $7.5(7-8) \mathrm{da}$. & $65.5(64.0-67.0)$ & $10.6(10.0-11.2)$ & $9.82(9.28-10.33)$ & $0.609(0.577-0.634)$ & $0.081(0.076-0.087)$ \\
\hline Wistar data & 65.0 & 9.4 & & 0.650 & 0.071 \\
\hline 9 Test M $21(20-23)$ da. & $68.0(66.0-69.0)$ & $10.2(9.5-11.5)$ & $9.90(9.12-11.20)$ & $0.975(0.839-1.034)$ & $0.137(0.114-0.157)$ \\
\hline 3 Control F 7 da. & $64.7(62.0-66.0)$ & $10.5(10.0-10.8)$ & $9.77(9.26-10.13)$ & $0.625(0.608-0.644)$ & $0.079(0.077-0.082)$ \\
\hline Wistar data & 65.0 & 9.9 & & 0.679 & 0.077 \\
\hline 8 Test F $22(21-28)$ da. & $69.8(66.0-76.0)$ & $10.5(9.5-11.5)$ & $10.20(9.13-10.88)$ & $0.996(0.934-1.035)$ & $0.135(0.105-0.164)$ \\
\hline 3 Control M 14(13-17) da. & $71.0(70.0-72.0)$ & $13.6(13.5-13.6)$ & $12.97(12.61-13.28)$ & $0.962(0.907-1.025)$ & $0.124(0.109-0.136)$ \\
\hline Wistar data & 71.0 & 11.8 & & 0.840 & 0.091 \\
\hline 6 Test M 47(42-59)da. & $82.3(77.0-87.0)$ & $14.2(13.1-15.9)$ & $12.50(11.34-13.27)$ & $1.045(0.972-1.088)$ & $0.176(0.153-0.186)$ \\
\hline 1 Control F 13 da. & 71.0 & 13.2 & 12.76 & 1.035 & 0.145 \\
\hline Wistar data & 71.0 & 12.5 & & 0.876 & 0.098 \\
\hline 3 Test F 42 da. & $78.3(76.0-80.0)$ & $13.8(13.0-14.9)$ & $12.82(12.21-13.72)$ & $1.005(0.923-1.059)$ & $0.184(0.160-0.196)$ \\
\hline 7 Control M 13(11-15)da. & $75.2(73.0-79.0)$ & $15.9(15.0-16.9)$ & $14.95(14.24-15.95)$ & $1.021(0.963-1.087)$ & $0.119(0.100-0.129)$ \\
\hline Wistar data & 75.0 & 13.6 & & 0.952 & 0.104 \\
\hline 6 Test M $69(64-72) \mathrm{da}$. & $86.8(83.0-89.0)$ & $15.5(14.4-17.0)$ & $14.29(13.45-15.57)$ & $1.073(0.961-1.145)$ & $0.199(0.174-0.211)$ \\
\hline
\end{tabular}


7 Control F 13(11-15)da. Wistar data

7 Test F $69(67-72)$ da

1 Control M 22 da.

Wistar data

1 Test M 139 da.

1 Control F 37 da.

Wistar data

1 Test F 316 da.

2 Control M 36(35-37)da.

Wistar data

4 Test M 412(374-428)da.

2 Control F 44 (43-45) da.

Wistar data

4 Test F 392(377-428) da.

2 Control M 47(46-48)da.

Wistar data

4 Test M 291(223-316)da.

1 Control F 53 da.

Wistar data

2 Test F 314(311-316) da

\begin{tabular}{|c|c|c|c|c|}
\hline $75.3(74.0-76.0)$ & $15.6(15.0-16.2)$ & $14.71(13.84-15.73)$ & $1.016(0.950-1.086)$ & $0.121(0.103-0.133)$ \\
\hline 75.0 & 14.3 & & 0.974 & 0.112 \\
\hline $84.9(81,0-88.0)$ & $16.1(14.0-17.1)$ & $14.86(13.20-15.67)$ & $1.117(1.084-1.180)$ & $0.207(0.188-0.225)$ \\
\hline 98.0 & 29.6 & 27.25 & 1.357 & 0.198 \\
\hline 98.0 & 26.2 & & 1.271 & 0.182 \\
\hline 18.0 & 30.0 & 28.67 & 1. 418 & 0.285 \\
\hline 6.0 & 44.5 & 39.99 & 1.444 & 0.262 \\
\hline 16.0 & 42.2 & & 1. 411 & 0.261 \\
\hline 130.0 & 42.4 & 39.63 & 1,636 & 0.409 \\
\hline $120.5(120.0-121.0)$ & $51.6(50.5-52.8)$ & $49.10(47.5-50.7)$ & 1. $554(1.521-1.588)$ & $0.300(0.296-0.303)$ \\
\hline 121.0 & 44.4 & & 1,448 & 0.265 \\
\hline $134.3(132.0-140.0)$ & $48.6(44.1-52.4)$ & $46.02(40.9-49.9)$ & $1.570(1.496-1.664)$ & $0.407(0.394-0.424)$ \\
\hline $122.5(121.0-124.0)$ & $53.3(50.0-56.5)$ & $48.55(45.2-51.9)$ & $1.427(1.350-1.505)$ & $0.282(0.276-0.287)$ \\
\hline 23.0 & 49,1 & & 1,45 & 0.287 \\
\hline $138.5(135.0-148.0)$ & $54.1(49.0-56.5)$ & $50.41(45.3-53.9)$ & $1.533(1.516-1.549)$ & $0.408(0.372-0.468)$ \\
\hline $140.5(140.0-141.0)$ & $76,5(76,0-77,0)$ & $71.95(70.5-73.4)$ & $1.500(1.429-1.571)$ & $0.322(0.294-0.351)$ \\
\hline 141.0 & 66.7 & & 1.569 & 0.338 \\
\hline $152.8(150.0-157.0)$ & $77.6(66.8-101.5)$ & $69.79(63.4-83.2)$ & $1.576(1.502-1.626)$ & $0.415(0.363-0.466)$ \\
\hline 137.0 & 73.0 & 67.85 & 1.487 & 0.312 \\
\hline 137.0 & 65.5 & & 1.540 & 0.341 \\
\hline $149.0(146.0-152.0)$ & $81.6(67.0-96.2)$ & $67.20(58.1-76.3)$ & $1.540(1.454-1.626)$ & $0.363^{5}$ \\
\hline
\end{tabular}


TABLE 2-Continued

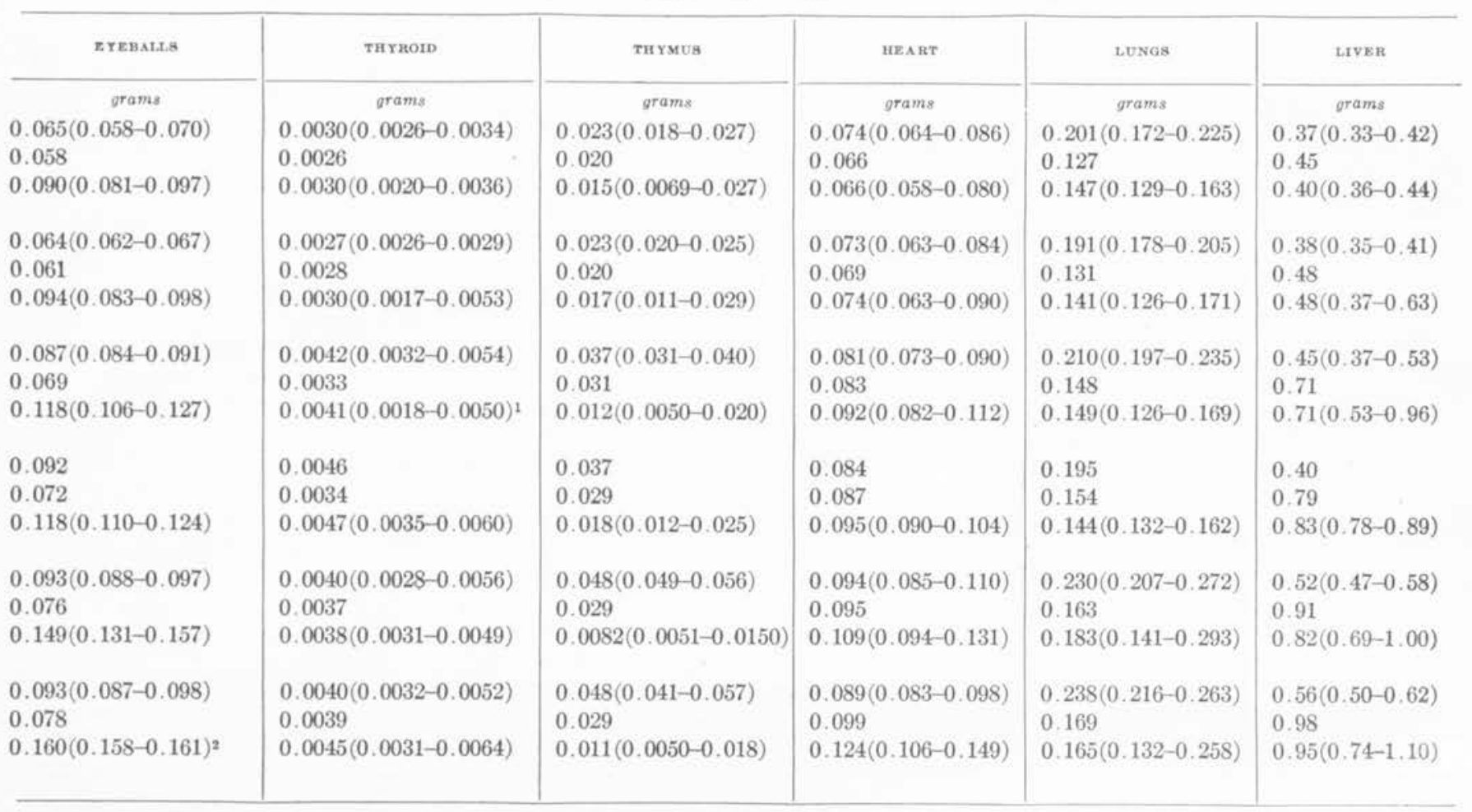


TABLE 2-Continued

\begin{tabular}{|c|c|c|c|c|c|}
\hline 0.124 & 0.0064 & 0.063 & 0.197 & 0.275 & 1.26 \\
\hline 0.109 & 0.0066 & 0.051 & 0.168 & 0.254 & 2.05 \\
\hline 0.230 & 0.0041 & 0.008 & 0.150 & 0.269 & 1.08 \\
\hline 0.159 & 0.0072 & 0.125 & 0.211 & 0.345 & 1.92 \\
\hline 0.136 & 0.0097 & 0.109 & 0.246 & 0.353 & 3.13 \\
\hline 0.233 & 0.0050 & lost & 0.299 & $1.536^{*}$ & 1.40 \\
\hline $0.161(0.161-0.162)$ & $0.0137(0.0118-0.0157)$ & $0.207(0.181-0.232)$ & $0.335(0.333-0.338)$ & $0.454(0.424-0.485)$ & $2.06(1.97-2.15)$ \\
\hline 0.140 & 0.0101 & 0.104 & 0.256 & 0.366 & 3.26 \\
\hline $0.287(0.262-0.314)$ & $0.0067(0.0054-0.0081)$ & $0.011(0.0078-0.0164)$ & $0.0263(0.242-0.276)$ & $0.659(0.567-0.835)^{3}$ & $2.04(1.66-2.60)$ \\
\hline $0.164(0.158-0.171)$ & $0.0074(0.0071-0.0077)$ & $0.119(0.115-0.122)$ & $0.276(0.258-0.293)$ & $0.371(0.364-0.379)$ & $2.79(2.65-2.94)$ \\
\hline 0.146 & 0.0110 & 0.144 & 0.276 & 0.393 & 3.53 \\
\hline $0.276(0.235-0.297)$ & $0.0074(0.0044-0.0108)$ & $0.022(0.010-0.037)$ & $0.286(0.238-0.371)$ & $0.401(0.395-0.407)^{4}$ & $2.46(1.54-4.15)$ \\
\hline $0.173(0.165-0.181)$ & $0.0142(0.0106-0.0178)$ & $0.275(0.250-0.299)$ & $0.380(0.369-0.391)$ & $0.474(0.456-0.493)$ & $4.19(3.57-4.81)$ \\
\hline 0.166 & 0.0139 & 0.160 & 0.349 & 0.492 & 4.47 \\
\hline $0.277(0.277-0.278)^{4}$ & $0.0085(0.0076-0.0090)^{3}$ & $0.0258(0.021-0.039)$ & $0.350(0.312-0.420)$ & $0.559(0.447-0.705)$ & $2.56(2.03-3.46)$ \\
\hline 0.184 & 0.0070 & 0.228 & 0.344 & 0.473 & 3.15 \\
\hline 0.165 & 0.0137 & 0.192 & 0.344 & 0.485 & 4,41 \\
\hline $0.125^{\mathrm{s}}$ & $0.0075^{5}$ & $0.037(0.035-0.038)$ & $0.366(0.340-0.393)$ & $0.616(0.548-0.685)^{5}$ & $2.75(1.84-3.66)$ \\
\hline
\end{tabular}


TABLE 2-Continued

\begin{tabular}{|c|c|c|c|c|}
\hline \multirow{2}{*}{ SPLEEN } & \multicolumn{2}{|c|}{ GTOMACR AND INTESTINES } & \multirow{2}{*}{ SUPRARENALB } & \multirow{2}{*}{ KIDNE Y } \\
\hline & Full & Empty & & \\
\hline grams & grams & grams & grams & grams \\
\hline $0.053(0.032-0.074)$ & $1.123(1.015-1.284)$ & $0.34(0.29-0.41)$ & $0.0027(0.0022-0.0032)$ & $0.125(0.111-0.138)$ \\
\hline 0.027 & & 0.29 & 0.0041 & 0.143 \\
\hline $0.026(0.020-0.032)$ & $0.773(0.668-0.935)$ & $0.43(0.35-0.53)$ & $0.0038(0.0032-0.0045)$ & $0.142(0.120-0.164)$ \\
\hline $0.048(0.042-0.059)$ & $1.080(1.032-1.148)$ & $0.38(0.32-0.46)$ & $0.0027(0.0024-0.0030)$ & $0.130(0.121-0.138)$ \\
\hline 0.029 & & 0.31 & 0.0044 & 0.151 \\
\hline $0.026(0.018-0.039)$ & $0.875(0.597-1.163)$ & $0.46(0.34-0.64)$ & $0.0050(0.0041-0.0070)$ & $0.167(0.136-0.223)$ \\
\hline $0.043(0.040-0.048)$ & $1.114(0.837-1.463)$ & $0.52(0.47-0.56)$ & $0.0042(0.0032-0.0050)$ & $0.153(0.127-0.168)$ \\
\hline 0,036 & & 0.55 & 0.0052 & 0.179 \\
\hline $0.057(0.034-0.108)$ & $2.481(1.746-3.923)$ & $0.83(0.70-1.05)$ & $0.0074(0.0066-0.0092)$ & $0.223(0.186-0.345)$ \\
\hline 0.041 & 1.033 & 0.59 & 0.0046 & 0.147 \\
\hline 0.039 & & 0.64 & 0.0055 & 0.188 \\
\hline $0.053(0.045-0.067)$ & $1.899(1.835-2.000)$ & $0.88(0.76-1.07)$ & $0.0070(0.0064-0.0074)$ & $0.210(0.203-0.222)$ \\
\hline $0.054(0.044-0.073)$ & $1.419(1.038-1.662)$ & $0.51(0.41-0.58)$ & $0.0041(0.0030-0.0048)$ & $0.180(0.161-0.207)$ \\
\hline 0.042 & & 0.78 & 0.0059 & 0.203 \\
\hline $0.061(0.034-0.095)$ & $2.092(1.748-2.504)$ & $0.92(0.64-1.17)$ & $0.0082(0.0070-0.0094)$ & $0.235(0.205-0.266)$ \\
\hline $0.053(0.047-0.066)$ & $1.437(1.038-1.814)$ & $0.52(0.41-0.65)$ & $0.0043(0.0030-0.0054)$ & $0.179(0.168-0.190)$ \\
\hline 0.045 & & 0.87 & 0.0062 & 0.211 \\
\hline $0.071(0.029-0.129)$ & $2.346(1.690-2.567)$ & $1.12(0.89-1.74)$ & $0.0097(0.0076-0.0128)^{3}$ & $0.261(0.241-0.328)$ \\
\hline
\end{tabular}




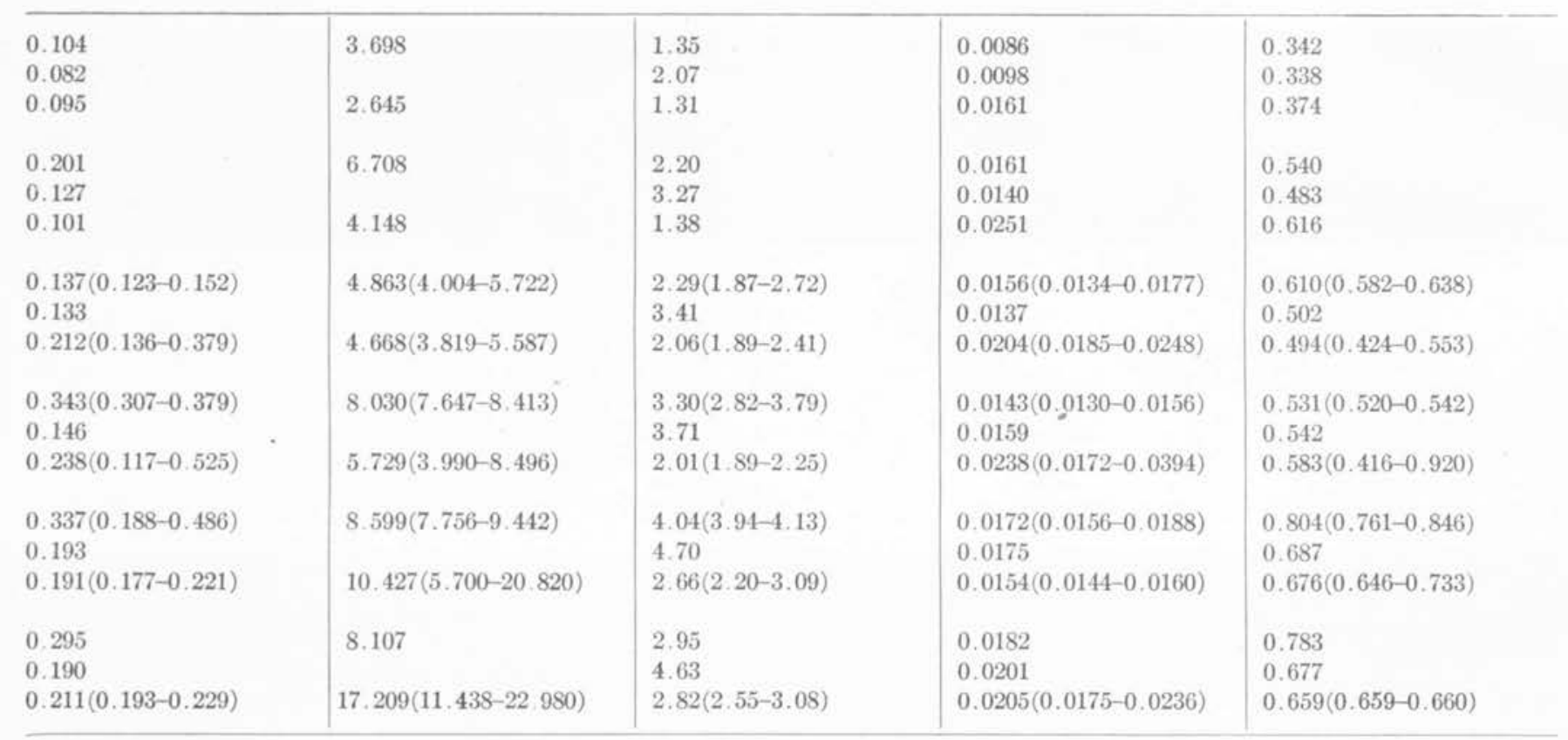


TABLE 2-Continued

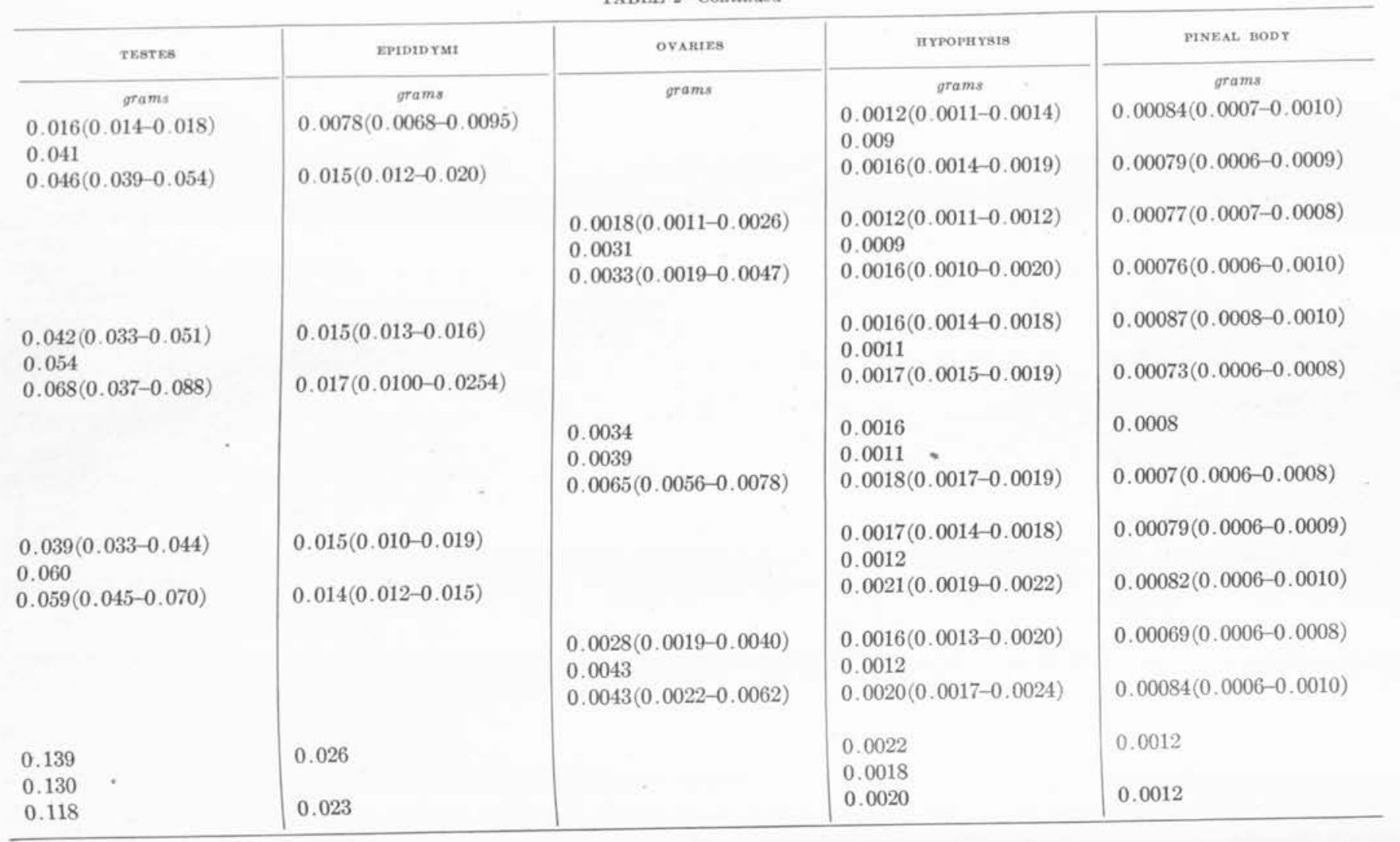




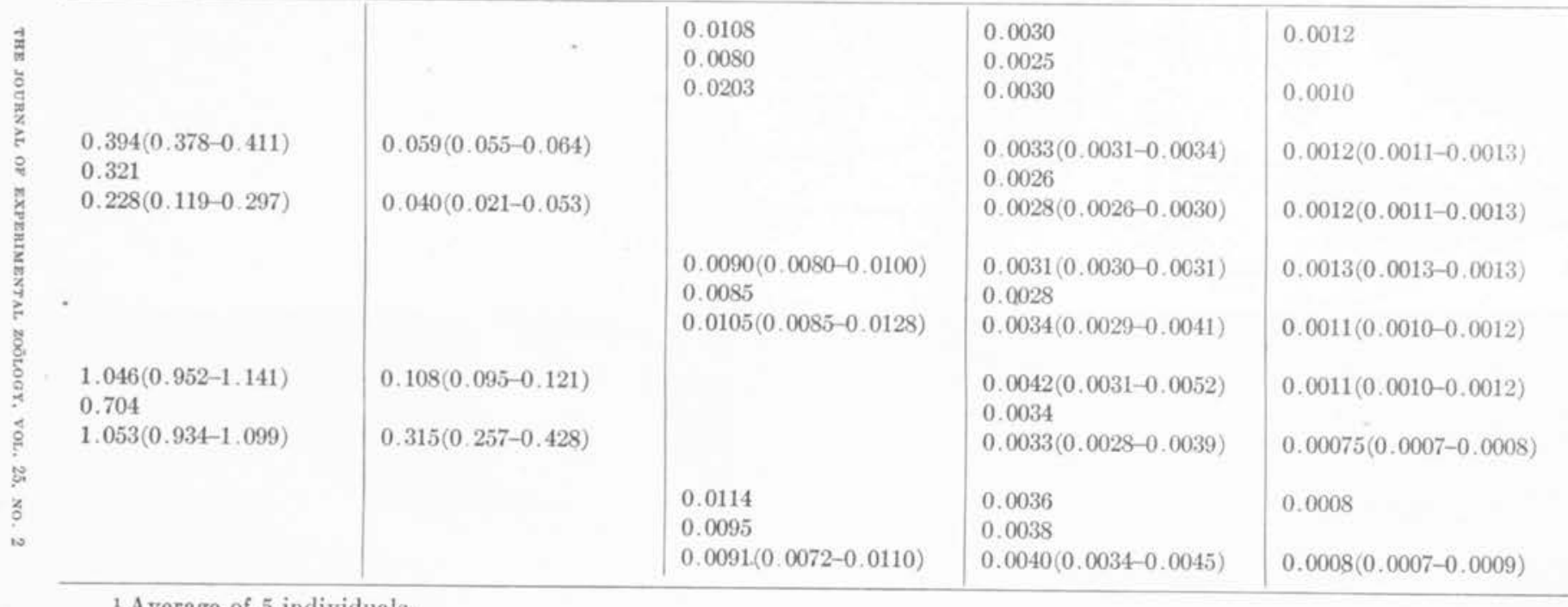

${ }^{1}$ Average of 5 individuals.

${ }^{2}$ Average of 6 individuals.

Average of 3 individuals.

${ }^{4}$ Average of 2 individuals.

Average of 1 individual.

- Pathological. 


\section{RATIO OF TAIL LENGTH TO BODY LENGTH}

Immediately after death each rat was laid on its back and gently extended. The distance from the tip of the nose to the anus, and from the anus to the tip of the tail was carefully measured. From the measurements thus obtained individual ratios between tail length and body length were computed. The average of these tail ratios expressed as percentage of the noseanus length is given in table 1 for each group of rats.

The data in table 1 show that with advancing age, the tail ratio increases in both the control and test rats. However, as compared with that in younger controls of corresponding body weight, the tail ratio, without exception, is much higher in the test rats. At ten weeks of age the ratio for the underfed individuals averages approximately 0.78 ( 73.9 per cent in the males and 82.0 per cent in the females), as compared with an average of 0.55 ( 53.7 per cent in the males and 56.6 per cent in the females) for the younger controls of corresponding weight. The differences at other ages, though somewhat less, are also very pronounced. It is therefore evident that in the underfed rats, the tail continues to grow in length more rapidly than the body. Thus the tail ratio in the underfed rats at ten weeks $(0.78)$ approaches, but does not quite reach, the normal ratio of 0.88 (Jackson '15 b) for (larger) rats of corresponding age.

In the rats underfed for very long periods, however, the data (table 1) indicate an elongation of the tail (ratio 0.89-0.93) even beyond the normal ratio for corresponding age. A similar condition was observed by Jackson ('15 b) in two cases.

It may further be noted in table 1 that in the controls (except at one week of age), and also in the test rats, the tail in most instances averages relatively longer in the female than in the male. The longer tail in the female, as well as the marked elongation of the tail in young rats held at maintenance, is in agreement with the observations by Jackson (' 15 b).

Hatai ('08) claimed that feeding rats upon an unsuitable diet of starch mixtures produced short-tailed individuals. Hatai ('15), however, found the tail length in five stunted rats fed upon 
a lipoid-free ration to exceed slightly the length given by the Wistar reference tables for normal rats of corresponding body length. Also in a later personal communication to Prof. C. M. Jackson he stated that in rats subjected to chronic inanition the tail becomes relatively long.

Harms ('09) observed that while starvation produced a marked decrease in the body length of Triton, the tail length remained practically unchanged. Morgulis ('11) however found the converse to be true in Diemyetylus.

Jackson ('15 a) found that acute and chronic inanition in adult albino rats also tends to produce relatively long-tailed individuals, due probably to a shrinkage in the trunk length.

\section{HEAD}

In the test rats underfed from birth to three and ten weeks of age, the absolute weight of the head (table 1) is slightly higher than in the controls of corresponding body weight. In the test rats at three weeks of age there is an appai nt increase from an average of 2.42 grams for the younger controls (sexes combined) to 2.83 grams, an increase of approximately 16 per cent (uncorrected for slight difference in body weight). The increase in head weight at this age is due in large part to the increase in the weight of the brain. At ten weeks of age, the increase of the head weight in the test rats (about 4 per cent) is very slight. At six weeks of age, the weight of the head for the underfed individuals ( 3.27 grams) is slightly lower than the average for the younger controls ( 3.40 grams). In the rats underfed for very long periods the weight of the head exceeds that in the controls 16 to 26 per cent.

In general, therefore, the data indicate that in very young rats underfed for considerable periods, the weight of the head slightly exceeds that of the younger controls of corresponding body weight, especially after very long periods of underfeeding.

Jackson ('15 b) similarly found in the majority of instances the head apparently to increase slightly in weight in young rats kept at maintenance for various periods. In adult rats subjected to both acute and chronic inanition Jackson ('15 a) found the 
head to become relatively large, due to the very sight loss of the head in weight, as compared with the loss in weight of the body as a whole.

\section{EXTREMITIES AND TRUNK}

According to Jackson and Lowrey ('12) the upper extremities (fore limbs) at one week of age normally form an average of 8.92 per cent of the body, the average net body weight being 11.6 grams. In my controls of the same age, but somewhat lighter in weight (9.8 grams net), the average relative weight of the upper extremities (6.9 per cent) is lower. This difference may be due in part to variation in the technique used in removal of the extremities, though in both cases they were divided at the shoulder joint.

As compared with my controls the weight of the upper extremities (table 1) is heavier in the test rats underfed from birth to three weeks of age. The apparent growth from 0.678 to 0.800 gram (sexes combined) represents an increase of about 18 per cent. In the case of the rats underfed longer periods the weights of upper extremities are variable, but in the majority of instances they are lighter in the test animals than in the controls. On the whole, the differences are not very striking.

In the case of the lower extremities (table 1), the average relative weight of the hind limbs (9.53 per cent) for my controls at one week, is slightly lower than the relative weight (11.97 per cent) obtained by Jackson and Lowrey ('12) for normal rats of the same age.

As compared with my controls, the data in general indicate no distinct change in the weight of the hind limbs in the test rats. In the case of the four males underfed until 291 days of age there is an apparent increase from 11.58 grams in the controls to 14.20 grams in the test rats. The lower extremities are also much heavier in the females underfed to 314 days of age as compared with the younger control of corresponding body weight. At all other ages, however, the differences are variable and much less marked. 
The weight of the trunk (table 1 ) is also variable, but in the majority of cases averages slightly lower in my test rats than in the controls. The differences, however, are small, and therefore, as in the case of the lower extremities, are of questionable significance.

On the whole, therefore, the data indicate that the weights of the extremities are practically normal in the test rats as compared with the younger controls of corresponding weight. The slight increase in the head, especially in the older groups, is apparently compensated for in most cases by a corresponding decrease in the weight of the trunk. Considerable allowance should be made, however, for experimental error and normal variability.

Jackson ('15 b) in somewhat similar experiments noted no distinct change in the body proportions. There was, however, an apparent slight increase in the head, counterbalanced by a corresponding decrease in the trunk and extremities. During inanition in adult rats, apparently both the head and the extremities increase in relative weight, whereas the trunk decreases (Jackson'15 a).

\section{INTEGUMENT}

In my young test rats underfed from birth to six and ten weeks of age, the weight of the integument (table 1) is considerably lower than in the controls. At 10 weeks of age the average decrease from 3.9 to 2.0 grams amounts to a loss of about 48 per cent. Jackson ('15 b) likewise observed that the integument suffers a considerable loss in weight in young rats held at maintenance for various periods. For my test rats underfed from birth to three weeks, however, the relative weight of the integument averages 21.13 per cent of the body weight, as compared with 21.05 per cent for the younger controls of corresponding body weight. Thus it is evident that in rats underfed from birth to three weeks there is practically no change in the weight of the integument, which is in marked contrast to the loss suffered in the test rats fasting for longer periods. The greater severity of the longer fasts as compared with the shorter period may account in part for the differences observed. This may be due to a 
stronger growth tendency in the integument during the early maintenance period, or to a stronger tendency to accumulation of fat in the normal integument in the later periods.

In the test rats underfed for very long periods and weighing between 30 and 50 grams, the weight of the integument averages still somewhat lower than in the controls of corresponding weight, although the difference is less marked than in the ten weeks' group. The weight of the integument in the test rats weighing approximately 70 grams at the end of long periods of underfeeding, however, averages considerably higher than in the corresponding controls.

Aron ('11) found the skin in dogs held at constant weight to show a slightly higher percentage of the body weight than in normal control dogs. In these experiments, however, as pointed out by Jackson (' $15 \mathrm{~b}$ ), if comparison had been made with the controls at the beginning of the experiment instead of at the end, the opposite conclusion might have been reached. During acute and chronic inanition in adult rats, Jackson ('15 a) found the integument to lose weight in nearly the same proportion as the whole body.

Although the integument as a whole in most cases suffers a marked loss in weight, it was nevertheless observed that the external ear (fig. 1) in the young stunted rats, steadily continues to increase in size, and also changes its form so as to approach the normal adult appearance. The continued growth of the external ear is probably associated with the growth tendency of its skeletal (cartilaginous) portion.

\section{SKELETON}

The ligamentous, moist cartilaginous and dry cartilaginous skeletons were prepared as described by Jackson ('15 b). The moist skeleton was dried to constant weight in an oven at $85^{\circ} \mathrm{C}$.

It is evident from the data in table 1 that the weight of the ligamentous skeleton is constantly higher in the test rats than in the controls of corresponding weight. In the test rats at ten weeks of age there is an apparent increase in the weight of the ligamentous skeleton from an average of 2.357 grams (sexes 
combined) for the younger controls to 2.915 grams for the underfed individuals. The increase amounts to near y 24 per cent (uncorrected for slight difference in body weight).

Similarly, the data for the moist cartilaginous skeleton (table 1) show a marked increase in the underfed rats. For the test ani-

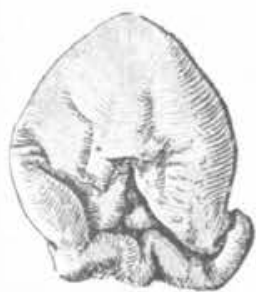

a

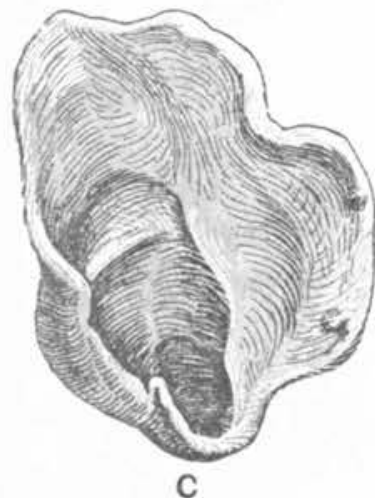

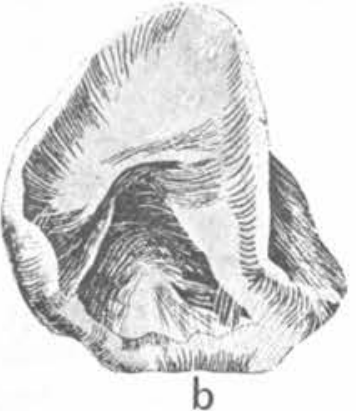

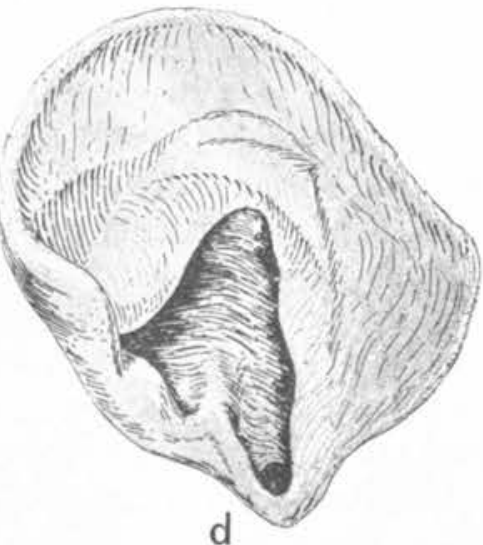

Fig. 1 a. External ear of a normal albino rat two weeks of age weighing 15.0 grams. $\times 4$. b. External ear of an albino rat underfed from birth to three weeks of age. Weight of rat was 11.5 grams. $\times 4$. c. External ear of an albino rat underfed from birth to ten weeks of age. Weight of rat was 15.4 grams. $\times 4$. d. External ear of a normal albino rat ten weeks of age weighing 89.0 grams. $\times 4$.

mals ten weeks of age the average absolute weight of the moist cartilaginous skeleton ( 2.470 grams) exceeds that for the younger controls ( 1.597 grams) by 0.873 gram, an excess of about 54 per cent. At other ages the differences are also very striking. 
The weight of the ligaments and periosteum (obtained by subtracting the weight of the moist cartilaginous from the weight of the ligamentous skeleton) apparently has decreased considerably in the test rats at three, six and ten weeks of age. For the last group there is an apparent loss in weight from an average of 5.12 per cent of the body weight in the controls, to an average of 3.04 per cent in the test rats. The data for the ligaments and periosteum at the end of the very long fasting periods are variable, but in the majority of instances there is an indication of an increase in the weight of this portion of the skeleton.

Jackson ('15 b) in similar experiments starting at three weeks of age, found the ligamentous skeleton to manifest a marked growth tendency during maintenance.

The alkaline solution in which the skeletons are boiled probably acts more severely on the tender skeletons of my young controls than on the tougher and more calcified skeletons of the older test rats, thus giving an abnormally high apparent weight for the ligamentous portion of the skeleton in the controls. This would no doubt tend to mask any actual increase in the ligaments and periosteum in the rats underfed for the shorter periods. This may account for the difference between my results in earlier periods of fasting and those obtained by Jackson for the ligamentous structures.

In the case of the dried cartilaginous skeleton the data (table 1) indicate a greater percentage of dry substance in the skeletons of the test rats than in the controls. At ten weeks of age the percentage of dry substance amounts to 23.4 per cent of the moist cartilaginous skeleton in the controls and 30.3 per cent in the test rats. Also at other periods (both older and younger) the percentage of dry substance in the skeletons of the test rats exceeds that for the controls.

It is evident, therefore, that during the underfeeding the skeleton had gained in solids and lost in water content. Thus the continued growth of the skeleton had proceeded along the lines of normal development, for Lowrey ('13) finds the dry substance of the normal ligamentous skeleton to increase steadily 
from an average of 33.3 per cent at twenty days of age to 52.6 per cent at one year.

Further evidence of growth continuing according to the normal process is indicated by the appearance of the third molar in the mandible and maxilla of the test rats underfed from birth to ten weeks of age. This tooth is not visible in the jaws of the younger controls with the same body weight.

The various individual bones of the skeleton in the underfed young rats are not only larger but also more advanced in their stage of development. The epiphyses at the ends of the humerus, especially at the distal end, are well fused with the shaft, much more so than in the case of the younger controls. Also the epiphyses at the ends of the femur and tibia are more completely developed in the test animals at ten weeks of age than in the controls, and in the former only has the tibia fused with the distal end of the fibula.

In general, therefore, the results confirm the observations of Jackson ('15 b) that during maintenance of body weight in young animals, not only skeletal increase in mass occurs, but also skeletal growth and differentiation of apparently normal character, though somewhat retarded in rate.

Waters ('08), who found that calves continue to increase in height and width of hip for a considerable time when held at maintenance, was probably the first to observe the fact that the skeleton continues to grow in young animals even when the body weight is held constant.

Aron ('11) noted an increase in the length and height of young dogs held at constant weight for considerable periods. He also found an increase in nine of the individual bones, but made no observations upon the entire skeleton. The first complete and systematic study of the growth of the skeleton in young animals held at maintenance was by Jackson ('15 b).

Birk ('11), Aron ('14), Hess ('16) and others show that a strong growth tendency of the skeleton is apparently manifested also in children during malnutrition.

During acute and chronic inanition in adult rats the skeleton nearly maintains its original weight (Jackson '15 a). 


\section{MUSCULATURE}

The absolute weight of the musculature (table 1) averages constantly higher (except in the four test males at 412 days, and in one female at 316 days) in the underfed rats than in the controls of corresponding body weight. The apparent increase in the individuals underfed from birth to ten weeks from 3.85 grams to 4.24 grams (sexes combined), however, represents an increase of only 10 per cent. The greatest excess is in the four test males at 291 days, in which the weight of the musculature exceeds that of the (younger) controls by about 20 per cent. At other ages, however, the differences are not very striking. In the exceptional cases mentioned above the average weight of musculature for the test rats is slightly below that for the (younger) controls of the same body weight.

In general, therefore, it appears that the musculature in the test rats differs only slightly from that of the controls. The averages, however, indicate a slight increase in weight in the majority of cases. On account of the difficulty in removing the musculature completely in a uniform manner, the exceptions may be due to experimental error, rather than to variability in the musculature.

Jackson ('15 b) likewise observed but slight change in the weight of the musculature in young rats kept at constant body weight, although in the majority of cases there was a slight tendency to increase. Since the tendency is even greater and more constant in my series, it may be concluded with a fair degree of certainty that in young rats of various ages held at maintenance for various periods the musculature shows a slight but definite tendency to increase in weight in the great majority of cases.

During both acute and chronic inanition in adult rats, Jackson ('15 a) found the musculature to lose relatively in nearly the same proportion as the whole body, the loss being somewhat greater in chronic than in acute inanition. 


\section{VISCERA}

The weight of the visceral group as a whole (table 1), including the abdominal and thoracic viscera, brain, spinal cord and eyeballs, in the rats underfed from birth to three, six and ten weeks of age, average constantly higher than in the corresponding controls. The increase in absolute weight amounts to approximately 28,29 and 38 per cent in the test rats at three, six and ten weeks respectively. In the rats underfed from 21 to 412 days of age the increase is less marked, while in the test rats weighing 75 grams at 291 days there is an apparent decrease in the weight of the visceral group from 13.68 to 11.19 grams, a loss amounting to approximately 19 per cent.

From the foregoing, it is evident that in rats underfed from birth to three, six and ten weeks of age, there is a distinct increase in the weight of the visceral group. In the older test animals the changes are less marked, in some instances actually showing a considerable loss in weight. My data, however, indicate an increasing tendency to loss of weight in the visceral group in prolonged retardation of body growth, although the individual viseera differ in this respect, as will appear later.

Jackson ('15 b) likewise found the visceral group to show a distinct increase in weight in rats kept at maintenance from three to six, eight and ten weeks of age, but found no essential change in the Iater periods. According to Jackson ('15 a) the visceral group undergoes little change in relative weight in adult rats during acute and chronic inanition.

\section{'REMAINDER'}

The weight of the 'remainder' (table 1), which includes some small unweighed organs, fat, and body-fluids, was obtained by deducting the weight of the integument, skeleton, musculature and viscera from the net body weight. The intestinal contents are therefore not included.

In the rats underfed from birth to three weeks of age the 'remainder' has apparently suffered an average decrease from 1.843 to 1.092 grams or a loss of approximately 40 per cent, which 
was compensated for by an increase in the skeleton and musculature. The marked decrease of the 'remainder' in these very young rats may possibly be due to a decrease in body fluids, the pereentage of which is very high in young rats (Jackson and Lowrey '12), (Lowrey '13).

In the later periods the data show considerable variability in the 'remainder,' but in most instances the weight of the 'remainder' is higher in the later periods.

Jackson ('15 b) found considerable variability in the 'remainder' of young rats held at maintenance beginning at three weeks or later, but considered it doubtful whether there is any definite change in the test rats, as compared with the normal. In adult rats subjected to acute or chronic inanition, however, Jackson ('15 a) found a definite decrease in the weight of the 'remainder,' probably due to loss of fat.

\section{BRAIN}

The weight of the brain (table 2) in the test rats underfed from birth to three weeks of age greatly exceeds that in either the corresponding controls or the Wistar norm for rats of the same body length as the controls. There is an increase from an average (sexes combined) of 0.616 gram for my controls to 0.985 gram in the test rats. This is an absolute increase of 0.369 gram, or a relative increase of about 60 per cent (uncorrected for slight differences in body weight). The average relative weight $(9.80$ per cent) of the brain in this group of test rats greatly exceeds the normal maximum of about 6.7 per cent of the body weight observed by Jackson ('13) for rats weighing approximately 15 grams.

In the rats underfed for longer periods the weight of the brain is more nearly equal in test rats and controls. As shown in table 2 , however, even in these groups the test rats (excepting the females at 42 days) slightly exceed the controls in absolute brain weight. The maximum apparent increase amounts to 13.3 per cent in the female at 316 days, and the average increase is about 5.8 per cent. This is subject to a small correction on account of slight differences in body weight. It may also be noted that the 
brain in my controls is usually heavier than the Wistar norm for rats of corresponding body length.

From the foregoing it is evident that in rats underfed from birth to three weeks of age there is a marked increase in the weight of the brain, whereas during the longer fasting periods (both in those beginning at birth and those beginning at three weeks) the increase is very slight. Bechterew ('95) found acute inanition in puppies and kittens to produce an apparent loss of weight in all of the organs, including to a slight extent the central nervous system. The greatest loss suffered by the central nervous system was apparently in the cerebral hemispheres, whereas the smallest loss was in the spinal cord. Microscopic examination revealed evidence of delayed medullation in fiber tracts not fully developed when the fasting started.

Hatai ('04) noted an apparent absolute decrease of 5 per cent in the weight of the brain in young rats suffering a loss of approximately 30 per cent in body weight due to an unfavorable diet of starch and beef-fat.

Later, Hatai ('08) found the brain weight in rats stunted by feeding upon an unfavorable diet, to be practically identical with that for normal younger rats of the same body weight.

Donaldson ('11) found the weight of the brain in a large series of rats held nearly at maintenance from 30 to 51 days of age to average 7.7 per cent less than that for the full-fed controls at the same age. However, he points out that if comparison be made with the caleulated initial brain weight, an increase of 3.6 per cent is apparent in the underfed rats. This in general agrees with the results of the present investigation.

Jackson ('15 b) observed practically no ehange in the weight of the brain in young rats held at maintenance for various periods starting at three weeks of age. My experiments started on much younger rats, and during a period when the brain normally shows a marked growth capacity. This probably accounts for the remarkable increase in brain weight observed for my youngest group. At later periods the brain loses its earlier intensity of growth, which is more nearly equalled by the remainder of the body. During acute and chronic inanition in adult rats the brain loses little if any in absolute weight (Jackson '15 a). 


\section{SPINAL CORD}

The weight of the spinal cord (table 2) like the brain in my controls averages slightly higher than the Wistar norm for rats of corresponding length, the only exceptions being the two control males and one control female weighing about 70 grams net. The differences are less marked when the body weight is used as a basis for comparison. As compared either with my controls or with the Wistar tables, the spinal cord is constantly heavier in the test rats. In the test rats at three and ten weeks of age, the average increase (sexes combined) amounts to approximately 70 per cent, and at six weeks to about 38 per cent. In the other groups of test rats underfed for long periods, the increase while still considerable, is somewhat less marked, varying from 29 to 56 per cent in the various groups (table 2 ).

Donaldson ('11) also found an increase in the weight of the spinal cord in rats held at 34 grams body weight from 30 to 51 days of age.

Jackson ('15 b) found that during maintenance there was a well-marked increase in the weight of the spinal cord, amounting to 36 per cent in those at maintenance from three to ten weeks of age.

It therefore appears that in young rats underfed at various ages the spinal cord shows a remarkable tendency to grow, this tendency being relatively strongest in those stunted from birth. This increase in weight is also maintained (to a lesser degree) in young rats underfed through long periods of time.

According to Jackson (' 15 a) the spinal cord suffers practically no loss in absolute weight during acute and chronic inanition in adult rats.

\section{EYEBALLS}

The weight of the eyeballs in my controls (table 2) averages constantly higher than the Wistar norm for rats of corresponding length. The differences, however, are not striking and are probably due largely to differences in body weight (my rats averaging slightly heavier than the Wistar norm for corresponding length). 
When the weight of the eyeballs for the controls is compared with the weight for the test rats, it is evident that a marked increase has occurred in the latter. At ten weeks of age the increase in weight from an average of $0.093 \mathrm{gram}$ in the controls to $0.155 \mathrm{gram}$ in the test rats, equals an increase of more than 66 per cent. At six and ten weeks of age the excess weight in favor of the test rats is less, being about 41 and 34 per cent respectively. The increase at later periods, in some instances is even more striking, amounting to approximately 73 per cent (sexes combined) in the rats weighing nearly 50 grams after very long periods of fasting.

My results, therefore, confirm Jackson's ('15 b) observation that the eyeballs show a marked growth capacity in young rats kept at maintenance for various periods. He suggests that the possibility of continued growth of the eyeballs is due largely to water absorption, the water content of the eyeballs being normally very high ( 85.6 per cent at 20 days according to Lowrey' 13 ).

The eyeballs suffer practically no loss in weight during acute and chronic inanition in adult rats according to Jackson ('15 a).

A few observations were made concerning the time at which the eyelids opened in my albino rats. The data (table 3) indicate that the eyelids opened in my controls at an average age of fifteen days, whereas in the test rats the opening is apparently delayed until about the seventeenth day. The body weight of the controls when the eyelids opened averaged 16.5 grams as compared with 9.9 grams for the test rats. Therefore, although somewhat retarded in time, the eyelids nevertheless opened at a lighter body weight in the underfed individuals than in the controls. However, in the case of one litter (St 63) it was noted that the eyelids opened in two test rats weighing an average of 12.2 grams even at a younger age ( 15 days) than in the control. The exact age at which the eyes opened in the controls in this instance was not recorded except that it occurred after the fifteenth day at a body weight of more than 15.5 grams.

Bechterew ('95) likewise found a delay in the opening of the eyelids in newborn dogs and cats subjected to acute inanition.

Several investigators have noted the age at which the eyes 
normally open in the albino rat. Jackson ('12) states that the eyes are opened at about sixteen or seventeen days of age. Donaldson ('15) ('The Rat,' p. 19) states that the eyes open from the fourteenth to the seventeenth days, most often on the fifteenth or sixteenth.

King ('16) states that usually the female rats in a litter open their eyes several hours sooner than do the males. The delay in the opening of the eyelids observed in my test rats apparently is not because the data, include a large majority of females, for

TABLE 3

Age and gross body weight at which the eyelids opened in the control and tests rats

\begin{tabular}{|c|c|c|c|c|c|c|}
\hline \multicolumn{4}{|c|}{ CONTROLS } & \multicolumn{3}{|c|}{ TEST RATS } \\
\hline Litter number & $\begin{array}{l}\text { Number of } \\
\text { individuals } \\
\text { and sex }\end{array}$ & $\begin{array}{l}\text { Age in } \\
\text { days }\end{array}$ & $\begin{array}{c}\text { Gross body } \\
\text { weight }\end{array}$ & $\begin{array}{l}\text { Number of } \\
\text { individuals } \\
\text { and sex }\end{array}$ & $\begin{array}{l}\text { Age in } \\
\text { days }\end{array}$ & $\begin{array}{c}\text { Gross body } \\
\text { weight }\end{array}$ \\
\hline & & & grams & & & grams \\
\hline St 56 & $1(\mathrm{~F})$ & 15 & 16.0 & $3(1 \mathrm{M}, 2 \mathrm{~F})$ & 18 & 7.9 \\
\hline St 59 & $1(\mathrm{~F})$ & 15 & 11.3 & $8(1 \mathrm{M}, 7 \mathrm{~F})$ & 18 & 8.6 \\
\hline St 63 & $1(\mathrm{~F})$ & $15+$ & $15.5+$ & $2(\mathrm{~F})$ & 15 & 12.2 \\
\hline St 68 & $1(\mathrm{M})$ & 17 & 20.0 & $1(\mathrm{~F})$ & 18 & 14.0 \\
\hline St 92 & $2(1 \mathrm{M}, 1 \mathrm{~F})$ & 15 & 20.0 & $2(1 \mathrm{M}, 1 \mathrm{~F})$ & 16 & 11.0 \\
\hline St 95 & & & & $1(\mathrm{M})$ & 18 & 11.0 \\
\hline St 102 & $1(\mathrm{~F})$ & 14 & 15.0 & $6(\mathrm{~F})$ & 17 & 10.2 \\
\hline St 106 & $1(\mathrm{~F})$ & 14 & 15.0 & $2(1 \mathrm{M}, 1 \mathrm{~F})$ & 19 & 10.5 \\
\hline St 114 & $2(1 \mathrm{M}, 1 \mathrm{~F})$ & 15 & 15.8 & & & \\
\hline Average*. & $10(3 \mathrm{M}, 7 \mathrm{~F})$ & 15 & 16.5 & $25(5 \mathrm{M}, 20 \mathrm{~F})$ & 17.5 & 9.9 \\
\hline
\end{tabular}

- Control of Litter St 63 excluded from the averages, as the exact time at which the eyelids opened was not recorded.

in practically every instance (see exception noted) the eyelids opened two or three days later in the test females than in the female controls of the same litter.

\section{THYROID GLAND}

In the test rats fasting from birth to three, six and ten weeks of age the weight of the thyroid gland (table 2) is practically identical with that in the controls. However, in the rats underfed for very long periods, in which the experiments started at three weeks of age, the weight of the thyroid in most instances 
shows a marked decrease in the test rats when compared with either my controls or with the Wistar norm tables. For example, in the case of the eight test rats weighing about 50 grams after very long underfeeding the thyroid has apparently suffered a loss of approximately 50 per cent in the males, although there is apparently no change in the females.

These latter results therefore agree in general with those obtained by Jackson (' $15 \mathrm{~b}$ ) in rats held at maintenance from the age of three to six, eight and ten weeks. In my younger rats, however, subjected to inanition for various periods starting at birth, the weight of the thyroid apparently remains practically unchanged. The power of maintenance in the thyroid therefore appears stronger in the very young rats. Considerable allowance should be made for experimental error due to the difficulty in dissecting the thyroid gland in an accurate manner.

During acute inanition in adult rats, Jackson ('15 a) reports that the thyroid gland apparently loses little or no weight, while in chronic inanition with an average loss in body weight of 36 per cent, the thyroid gland loses only about 22 per cent in weight.

\section{THYMUS}

As is evident from table 2, the weight of the thymus is, without exception, much lighter in the test rats than in the controls. At three, six and ten weeks of age the loss in weight amounts to approximately 30,60 and 80 per cent respectively. The decrease in weight of the thymus in the test rats, while very marked in all groups, is especially striking in the four test males underfed 412 days. From an average of 0.207 gram in the controls, the weight in the test rats has decreased to 0.011 gram, a loss of approximately 94 per cent. This decrease is not so remarkable, however, when the normal involution with age is taken into account. According to the Wistar tables, the normal weight of the thymus at 400 days is only 0.039 gram.

Thus it is evident, as was observed by Jackson (' 15 b) that the thymus loses markedly in weight in young rats underfed for various periods. He found a loss of about 90 per cent for the 
thymus in rats held at maintenance from the age of three to ten weeks.

Jonson ('09) likewise found in young rabbits kept at constant body-weight for four weeks the weight of the thymus to be reduced to about one-thirtieth its initial value. The greatest loss is suffered by the cortex, which is reduced to one-twelfth of its initial weight during two weeks of maintenance. Judging from comparison with my own results, as well as with those of Jackson, the process of hunger involution of the thymus would appear to be much more rapid and complete in the rabbit than in the rat.

\section{HEART}

The weight of the heart (table 2) in the rats underfed from birth to three weeks of age differs but little from that in the controls (decrease of about 10 per cent in the males; slight increase in the females). At six and ten weeks of age, however, there is an evident increase in the heart weight. In those underfed from birth to six weeks, the average increase is about 13 per cent. For the groups underfed to ten weeks, the increase from an average of 0.092 gram in the controls to 0.117 gram in the test rats (sexes combined) represents an increase of about 27 per cent (subject to slight correction for differences in body weight). In the rats underfed for very long periods, the heart weight, while variable in most instances, is lower than in the controls. There is a decrease in the various groups, varying from about 8 to 29 per cent, excepting the four females at 392 days, which show an apparent increase of about 3 per cent (most of which may be accounted for as due to difference in body weight).

In general, therefore, the data indicate a slight increase in the weight of the heart in the test rats at six and ten weeks of age, while during the later periods the heart apparently lost weight in the majority of instances. However, on account of the normal very considerable variability of the heart weight, especially in young rats (Jackson '13), the apparent changes in the heart during underfeeding are probably somewhat doubtful.

In young rats kept at constant body weight for various periods, 
and also in adult rats subjected to acute and chronic inanition Jackson ('15 a, '15 b) found the percentage weight of the heart to remain practically unchanged. Apparently the effects were less marked than in my experiments, in which the underfeeding was begun earlier, or carried over longer periods.

\section{LUNGS}

As compared with the Wistar norm for rats of corresponding body length, the weight of the lungs (table 2) appears to be unusually high in my young controls. For the largest group (14 rats, 7 males and 7 females, 13 days old) weighing about 15 grams, the average absolute weight of the lungs (sexes combined) is 0.234 gram, as compared with the Wistar average of 0.166 gram for rats of corresponding body length.

Jackson ('13) found the normal weight of the lungs in the rat at one week to average 0.1938 gram, with which my average of 0.1995 gram for controls of the same age agrees closely. It appears, therefore, as pointed out by Jackson ('13), that weights for the lungs derived from Hatai's formula appear much lower than the actual observed values in very young rats.

As compared with my controls, the average weight of the lungs is low in the test rats at three, six and ten weeks of age, the decrease in each case amounting to a loss of approximately 26 per cent (subject to slight correction for difference in body weight).

In the longer experiments the lungs average heavier for the underfed rats than in the controls, with the exception of one female at 139 days. The presence of lung infection among the older underfed rats probably accounts in part at least for the increase in the weight of the lungs. The data for the test rats weighing about 70 grams after very long fasting also include the weights of the lungs for five rats which were asphyxiated. In these instances the weights would no doubt be high due to the greater amount of blood retained'in the lungs. Therefore the effect of the very long fasting period upon the weight of the lungs is doubtful.

Jackson ('15 b) found that in young rats subjected to maintenance for various periods, the lungs show a slight decrease in 
weight during the earlier periods (decrease of 15 per cent) but not later. It is evident from my results that the loss in the lung weight in very young underfed rats is considerably greater.

During acute and ehronic inanition in adult rats the lungs lose weight in about the same proportion as the whole body (Jackson '15 a).

\section{LIVER}

The weight of the liver (table 2) in my young control rats is very much lower than the Wistar norm for rats of corresponding body length. The differences are especially marked in the controls weighing approximately 13 and 15 grams. My average value of 0.37 gram at one week, however, corresponds rather closely with the weight of 0.3431 gram obtained by Jackson ('13) in rats of the same age and weight. Thus, as pointed out by Jackson, it seems that weights for the liver obtained by Hatai's formula, especially for young rats, are much too high, at least for rats of the Missouri and Minnesota colonies. The difference appears too great to be attributed to normal variability or to slight differences in diet. However, C. Watson (10) finds a marked decrease in the relative size of the liver in eaptured wild rats fed upon bread and milk diet used during eaptivity; and Jackson ('13) has emphasized the marked and irregular variability found
in the liver of the rat.

In the rats underfed from birth to three, six and ten weeks of age the weight of the liver is considerably higher than in the corresponding controls. The increase at three weeks averages about 17 per cent. The difference is especially marked, however, at six and ten weeks, amounting to an average increase of about 83 per cent in the former and 64 per cent in the latter (subject to correction for slight differences in body weight).

In the rats underfed for longer periods the liver is variable. At 412 days of age the average weight of the liver (2.04 grams) in trols (2.06 grams). The lically identical with that in the two conbe abnormally low, however. rats underfed for very long 
sicirably lower than in the corresponding controls. At 291 days of age there is an apparent deerease in the weight of the liver from 4.19 grams to 2.56 grams, a loss of about 39 per cent (uncorrected for slight difference in body weight).

In general therefore the data indieate that in young rats underfed for various periods, the liver shows a marked growth tendency in the very young rats, while in the very long fasting experiments there is usually a marked decrease in the weight of the liver.

Jackson ('15 b) likewise found that in young rats (three weeks old or more) held at maintenance the liver increases slightly (about 10 per cent) in weight during the shorter fasting periods; but in experiments extending over longer periods there is a decided decrease in the liver weight.

During inanition in adult rats, the liver loses in weight relatively more than the whole body, and to a greater extent in acute than in chronic inanition (Jackson '15 a).

\section{SPLEFN}

From table 2 it is very evident that in my young controls weighing approximately 10,13 and 15 grams, the weight of the spleen greatly exceeds the Wistar norm for the spleen in rats of corresponding body-length. This is especially true for the youngest group. However, my average weight for the spleen $(0.051 \mathrm{~g}$.) at one week agrees more nearly with Jackson's ('13) normal spleen weight $(0.0425 \mathrm{~g}$.) at the same age. It has been noted by Jackson ('13) that the weight of the spleen derived from Hatai's formula is in general somewhat too low, probably because Hatai (without apparent justification) excluded all 'enlarged' spleens from his data.

The weight of the spleen (table 2) at three weeks of age is considerably lower in my test rats than in the controls. In this group there has been an apparent decrease from 0.051 to $0.026 \mathrm{gram}$, a loss of about 49 per cent (uncorrected for slight difference in body weight).

In the rats underfed from birth for longer periods (up to six 
and ten weeks), however, the spleen shows a marked tendency to growth, the average apparent increase being about 27 per cent.

In rats underfed for longer periods, beginning at three weeks of age, on the contrary, there is an apparent decrease in the weight of the spleen, except in the four females at 412 days. On account of the extreme normal variability of the spleen, however, the apparent atrophy during the later fasting periods may be of doubtful significance. It is nevertheless in agreement with the doctrine that lymphoid tissues in general tend to atrophy during inanition (cf. Jolly et Levin, '11).

Jackson ('15 b) noted a reduction in the weight of the spleen in young rats during the earlier periods of underfeeding (beginning at three weeks), while at later periods there was no material change in weight. In adult rats during chronic inanition the average loss in weight is nearly proportional to that of the entire body while in acute inanition the loss appears very much greater (Jackson'15 a).

\section{STOMACH AND INTESTINES}

The average weight of the stomach and intestines (including contents) is 1.10 grams (table 2) for my controls at one week. This is somewhat higher than the normal weight 0.733 gram obtained by Jackson ('13) for a large series of the same age. The difference is not entirely due to a difference in the amount of the contents, for the weight of the empty alimentary canal $(0.36$ gram) likewise averages higher than Jackson's weight $(0.296$ gram).

The weight of the contents of the alimentary canal (obtained by deducting the weight of the empty from the full alimentary canal) is much lower at three weeks in the test rats than in the controls. At six and ten weeks of age, however, the weight of the contents is excessively heavy in the underfed rats. In the later periods of underfeeding the data are variable but show a tendency to decrease.

Jackson (' 15 b) noted an increase in the contents of the alimentary canal during the early periods of underfeeding, while during the longer experiments the change (a tendency to decrease) was 
less marked. This is in agreement with my findings, excepting the youngest group.

As compared with my controls, the weight of the empty alimentary canal is higher in the test rats at three, six and ten weeks of age than in the controls. At ten weeks of age the weight of the empty digestive canal apparently has nearly doubled in the underfed animals.

At the later periods, however, the data indicate a reduction in weight of the empty alimentary canal, which is especially striking (34 per cent decrease) in the 4 males weighing about 75 grams at 291 days of age.

Jackson ('15 b) likewise found the empty alimentary canal to increase in weight during the shorter maintenance periods, after which there was a decline in weight.

During both acute and chronic inanition in adult rats there is a very marked decrease in the weight of the stomach and intestines, both with and without contents (Jackson '15 a.).

\section{SUPRARENAL GLANDS}

The average weight of the suprarenals (table 2 , sexes combined) $(0.0027$ g. $)$ for my controls at one week agrees fairly with the normal average $(0.00226$ g.) obtained by Jackson ('13), but is far below the weight given in the Wistar tables for rats of corresponding body length. Thus the weights for the suprarenals at one week derived from Hatai's formula seem much too high, at least for normal rats from the Missouri and Minnesota colonies. For the controls at 13 and 14 days of age (table 2) the difference is less marked.

As compared with my controls, the weight of the suprarenals (except in the four males at 291 days) is constantly higher in the test rats. The average increase in the weight of the suprarenals (sexes combined) in the test rats at three and six weeks of age amounts to more than 60 per cent (uncorrected for slight difference in body weight). At ten weeks of age the difference has reached a maximum average of approximately 114 per cent. At later periods (except in the four males at 291 days, in which 
instance there was a loss of about 11 per cent) the suprarenals in the test rats exceed those of the corresponding controls 12 to 87 per cent. It should be noted that the weight of the suprarenals is slightly higher in the test females than in the males of corresponding body weight at ten weeks of age and also at all subsequent periods, thus indicating the appearance of sexual differentiation during underfeeding.

Jackson ('15 b) also found the suprarenals to manifest a marked growth tendency in young rats held at maintenance. He noted a maximum increase of 39 per cent in the female underfed from three to ten weeks of age. Apparently the growth of the suprarenals was less marked than in my experiments, in which the underfeeding was begun earlier or carried over longer periods. As occurs normally, the suprarenals during underfeeding underwent sexual differentiation in weight, also confirming the results of Jackson. In adult rats, there is but little loss in the absolute weight of the suprarenal glands during inanition (Jackson '15 a).

\section{KIDNEYS}

Using my controls as a basis for comparison, there is apparently an increase in the weight of the kidneys (table 2) in the rats underfed from birth to three, six and ten weeks of age. The apparent average increase (uncorrected for difference in body weight) amounts to about 21 per cent at three weeks, 45 per cent at six weeks, and 38 per cent at ten weeks.

In the rats underfed for very long periods the weight of the kidney is variable, some showing an increase and others a decrease. Due to this inconstancy in results, the changes are of questionable significance.

In general therefore it appears that, as was observed by Jackson ('15 b) the kidneys tend to increase in weight during the earlier periods of the experiment, but show no definite change during later periods. The increase in my young rats is more striking than the increase observed by Jackson. This is probably due to the fact that my rats were placed upon the experiment at a younger age, when the intensity of growth in the kidney is greater.

In adult rats during acute and chronic inanition Jackson ('15a) 
found the kidneys to lose weight relatively slightly less than the entire body.

\section{TESTES AND EPIDIDYMIDES}

From the data in table 2 it can be seen that the Wistar data for the testes greatly exceed the corresponding weights for my control rats at 7 and 13 days of age. At one week the difference $(0.016$ to $0.041 \mathrm{gram}$ ) is especially striking. However the combined average weight of the testes and epididymides $(0.0238 \mathrm{~g}$.) for my controls at one week corresponds closely with Jackson's ('13) normal $(0.0273 \mathrm{~g}$. $)$ at the same age. It is therefore apparent that the Wistar data are much too high for these young rats. For the older controls, my data correspond fairly well with the Wistar tables.

Using my controls for comparison the weight of the testes in the test rats is exceedingly high at three, six and ten weeks of age. At three weeks the weight of the testes in the test rats exceeds that for the younger controls of the same body weight approximately 188 per cent. At six and ten weeks of age the increase (uncorrected for differences in body weight) amounts to about 62 and 51 per cent respectively, having become progressively less.

'In the rats weighing 75 grams at 291 days the weight of the testes is practically identical with that for the controls. At 139 and 412 days of age, however, the testes have evidently suffered a marked loss in weight. The decrease ( 0.394 gram to 0.228 gram) in the test males of the latter group amounts to a loss of about 42 per cent.

From the foregoing it is evident that in young rats the testes increase considerably during the shorter periods of underfeeding. With very prolonged stunting, however, the testes may show practically no change, or a loss which varies up to a considerable amount. Jackson ('15 a) noted an increase of 34 per cent in the weight of the testes in young rats held at constant body weight from three to ten weeks of age. My results are much more striking, however, which is probably due to the stronger growth tendency of the testes in my very young rats which were underfed from birth. Considerable caution must be exercised in drawing 
conclusions, however, on account of physiological variability in the weight of the testes.

The weight of epididymides (table 2 ) in my test rats of three and six weeks of age is higher than for the corresponding controls. For the youngest group there is an apparent increase from a normal weight of 0.0078 gram to 0.0154 gram an increase of over 95 per cent (uncorrected for slight difference in body weight). At six weeks of age the excess weight for the epididymides in the test rats is only 13 per cent.

In the rats underfed to ten weeks of age and also in those at 412 days, there is an apparent loss in the weight of the epididymi. The loss at ten weeks amounts to approximately 6 per cent, and at 412 days to about 32 per cent. However, in the test rats weighing 67.2 grams net at 291 days there is an apparent increase in the weight of the epididymi from 0.108 to 0.315 gram. In all cases the percentage losses above estimated are subject to correction for slight difference in body weight.

In general, therefore, the data indicate that in the youngest rats there is a marked increase in the weight of the epididymides, but that later there is a loss of weight in most cases.

Jackson ('15 b) found an apparent slight loss in the epididymides in rats held at constant body weight from three to six and ten weeks of age. In adult rats during inanition Jackson ('15 a) found that the testes and epididymides apparently lose weight in about the same proportion as the entire body.

\section{OVARIES}

The weight of the ovaries (table 2 ) in my controls at seven days of age $(0.0018 \mathrm{~g}$. $)$ is very much lower than the Wistar norm $(0.0033 \mathrm{~g}$.) for corresponding body length. The difference amounts to more than 80 per cent. Jackson ('13) found the weight of the ovary to average $0.00121 \mathrm{~g}$. at one week of age, which is even lower than my data. It therefore appears fairly certain that the weight of the ovary calculated from Hatai's formula is too high for this early period. At later ages my data do not differ so greatly from the Wistar tables. 
In my rats underfed from birth to three, six and ten weeks of age, there is apparently a considerable increase in the weight of the ovary. At ten weeks the increase from an average of 0.0028 gram in the controls to 0.0043 gram in the test rats represents a gain of approximately 54 per cent (uncorrected for body weight). At three and six weeks of age the differences are greater, amounting to 83 and 91 per cent respectively.

The data for the ovaries in the females subjected to very long periods of fasting are variable, but in most instances show a tendency to increase. Conclusions, however, are hazardous on account of the small number of observations and also on account of the extremely great cyclic changes in the weight of the ovary due to ovulation. Also the normal growth curve of the ovary is very complicated, as shown by Hatai ('13).

Jackson ('15 b) observed in the ovaries a decrease of about 27 per cent in weight in young rats kept at constant body weight from three to ten weeks of age. His data, however, indicate a slight increase in the youngest group underfed from three to six weeks. My results would indicate that at earlier periods the growth impulse of the ovary in underfed rats is still stronger, resulting in a marked increase in its weight.

\section{HYPOPHYSIS}

The weight of the hypophysis (table 2) appears higher in my controls (except for the one female weighing about 70 grams) than the Wistar norm for rats of corresponding body length. The high weight for the gland in my controls ean be attributed partly to differences in body weight, my rats being slightly heavier than the norm for corresponding body length.

As compared with my controls, the weight of the hypophysis at three, six and ten weeks of age is higher in the test rats than in the controls. At three and ten weeks of age the increase (sexes combined) for the test rats amounts to approximately 33 and 24 per cent respectively (uncorrected for slight difference in body weight). At six weeks of age the increase is less, amounting to about 8 per cent. There is apparently no sexual difference in the increase at these ages. 
In the test rats underfed for very long periods, however, the hypophysis is variable. In the test males at 412 days there is an apparent average decrease in absolute weight from 0.0033 gram to 0.0028 gram, a loss of over 15 per cent. The decrease in the males at 291 days of age amounts to approximately 21 per cent. On the other hand, in the females fasting for long periods there is no such decrease. In fact for the one female at 316 days the weight of the hypophysis shows no change, whereas at 392 and 314 days there is an apparent average increase of approximately 10 and 11 per cent respectively (subject to slight correction for difference in body weight). It should be noted that the weight of the hypophysis is slightly higher in the very old test females than in the males, suggesting that sexual differentiation in weight has occurred.

In general, therefore, it appears that the hypophysis increases considerably in weight in underfed rats during the earlier periods. In the very long experiments however the sexes appear to react differently. The weight of the hypophysis in the males apparently suffers a loss during very prolonged fasting, but in the females it shows a slight increase in weight. Jackson ('15 b) similarly noted a distinct tendency to an increase with the appearance of sexual differentiation in the weight of the hypophysis in rats held at constant weight from three to ten weeks of age. During inanition in adult rats the relative weight of the hypophysis is practically unchanged (Jackson' $15 \mathrm{a}$ ).

Quite recently Jackson ('17) has studied the volume-changes in the lobes of the hypophysis in rats underfed for various periods. In young rats kept at eonstant body weight the pars anterior is somewhat reduced in relative size, the intermedia and nervosa becoming correspondingly larger.

\section{PINEAL BODY}

The weight of the pineal body (table 2 ) is practically normal in each group of test rats when compared with the corresponding controls. The slight differences which exist (especially in some of the older groups) are of doubtful significance, especially when the exceedingly small size of the gland is taken into consideration. 
Considerable allowance must be made for experimental error, and for variability (the extent of which is unknown).

The data for the control rats indicate no sexual difference in the weight of the gland at the ages observed. Hoskins ('16) likewise found no significant difference according to sex.

\section{DISCUSSION}

In general, the results of the present investigation concerning the effects of underfeeding upon very young rats and upon slightly older rats underfed for very long periods agree fairly well with those obtained by Jackson ('15 b) in rats held at maintenance for various periods beginning at three weeks of age. There are, however, certain differences found in my rats in which the underfeeding began shortly after birth, or was prolonged for very considerable periods. These differences are probably due chiefly to the varying tendencies to growth and maintenance among the various organs at different periods.

With reference to their growth tendency in young rats held at constant body weight, the organs are divided by Jackson ('15 b) into three classes: (1) those having a growth tendency so strong that they continue to increase, even when the body weight is held constant; (2) those which approximately hold their weight constant (variation within 10 per cent) under these conditions; and (3) those which are unable to maintain themselves and lose in weight.

The distribution of the organs according to this scheme for my rats underfed from birth to ten weeks, also for those weighing about 50 grams after very long periods of fasting, together with Jackson's ('15 b) results for rats underfed from three to ten weeks are shown in table 4.

On comparing my results with Jackson's it appears that in very young rats underfed from birth to ten weeks of age a larger number of organs show a tendency to increase than in rats underfed from three to ten weeks. On the other hand, very long fasting apparently adds to the number of organs which fall into the group showing approximate maintenance or a tendency toward loss in weight. 
TABLE 4

Comparison, of growth tendency; (1)in young rats underfed from birth to ten weeks; (2) in young rats held at maintenance from three to ten weeks; and (9) in rats weighing approximately 50 grams after very long fasting

\begin{tabular}{|c|c|c|c|c|c|c|}
\hline , & $\begin{array}{l}\text { MARKED TENDENCY TO } \\
\text { GROWTH DURING } \\
\text { UNDEHEEEDNG }\end{array}$ & $\begin{array}{l}\text { PER CENT } \\
\text { OF CHANGE }\end{array}$ & $\begin{array}{l}\text { WRTOHT NEARLX } \\
\text { CONSTANT DCRING } \\
\text { UNDERTERDING }\end{array}$ & $\begin{array}{l}\text { PER CENT } \\
\text { OF CHANGE }\end{array}$ & $\begin{array}{l}\text { MAIKKED LOSS IN } \\
\text { WRIGHT DURING } \\
\text { UNDERFEDING }\end{array}$ & $\begin{array}{l}\text { PER CENT } \\
\text { OF CBANGE }\end{array}$ \\
\hline $\begin{array}{l}\text { Rats underfed from birth to } \\
\text { ten weeks of age (Stewart) }\end{array}$ & $\begin{array}{l}\text { Suprarenals } \\
\text { Alimentary canal } \\
\text { Spinal cord } \\
\text { Eyeballs } \\
\text { Liver } \\
\text { Ovaries } \\
\text { Testes } \\
\text { Kidneys } \\
\text { Heart } \\
\text { Spleen } \\
\text { Hypophysis } \\
\text { Skeleton }\end{array}$ & $\begin{array}{l}+114 \\
+100 \\
+70 \\
+66 \\
+64 \\
+54 \\
+51 \\
+38 \\
+27 \\
+24 \\
+24 \\
+24\end{array}$ & $\begin{array}{l}\text { Musculature } \\
\text { Brain } \\
\text { Thyroid } \\
\text { Epididymi }\end{array}$ & $\begin{array}{l}+10 \\
+8 \\
+4 \\
-6\end{array}$ & $\begin{array}{l}\text { Thymus } \\
\text { Integument } \\
\text { Lungs }\end{array}$ & $\begin{array}{l}-80 \\
-48 \\
-26\end{array}$ \\
\hline $\begin{array}{l}\text { Rats held at constant body } \\
\text { weight from three to ten } \\
\text { weeks of age (Jackson) }\end{array}$ & $\begin{array}{l}\text { Eyeballs } \\
\text { Spinal cord } \\
\text { Testes } \\
\text { Skeleton } \\
\text { Alimentary canal } \\
\text { Suprarenals } \\
\text { Hypophysis }\end{array}$ & $\begin{array}{l}+50 \\
+36 \\
+34 \\
+28 \\
+28 \\
+12 \\
+39 \\
+18 \\
+19\end{array}$ & $\begin{array}{l}\text { Liver } \\
\text { Kidneys } \\
\text { Musculature } \\
\text { Brain } \\
\text { Heart }\end{array}$ & $\begin{array}{l}+10.3 \\
+\quad 4.1 \\
+\quad 3.0 \\
-0.5 \\
-0.6\end{array}$ & $\begin{array}{l}\text { Thymus } \\
\text { Spleen } \\
\text { Integument } \\
\text { Ovaries } \\
\text { Thyroid } \\
\text { Lungs }\end{array}$ & $\begin{array}{l}-90 \\
-42 \\
-36 \\
-27 \\
-24 \\
-15\end{array}$ \\
\hline $\begin{array}{l}\text { Rats weighing about } 50 \text { grams } \\
\text { after very long periods of } \\
\text { fasting (twenty-one to about } \\
\text { four hundred days) (Stewart) }\end{array}$ & $\begin{array}{l}\text { Eyeballs } \\
\text { Spinal cord } \\
\text { Suprarenals } \\
\text { Skeleton } \\
\text { Ovaries }\end{array}$ & $\begin{array}{l}+73 \\
+40 \\
+31 \\
+66 \\
+32 \\
+17\end{array}$ & $\begin{array}{l}\text { Lungs } \\
\text { Hypophysis, F } \\
\text { Brain } \\
\text { Musculature } \\
\text { Spleen } \\
\text { Kidneys } \\
\text { Liver } \\
\text { Heart }\end{array}$ & $\begin{array}{l}+28(?) \\
+10 \\
+4 \\
+4 \\
-5 \\
-6 \\
-7 \\
-10\end{array}$ & $\begin{array}{l}\text { Thymus } \\
\text { Testes } \\
\text { Epididymi } \\
\text { Alimentary canal } \\
\text { Thyroid } \\
\text { Hypophysis M } \\
\text { Integument }\end{array}$ & $\begin{array}{l}-90 \\
-42 \\
-32 \\
-27 \\
-36 \\
-15 \\
-11\end{array}$ \\
\hline
\end{tabular}


Thus the liver, ovaries, kidneys, heart and spleen show a marked tendency to increase in weight in the rats underfed from birth to ten weeks, but not in those underfed from three to ten weeks. On the other hand, in my rats fasting for very long periods, the hypophysis (in the males), alimentary eanal, testes and epididymi show a marked loss in weight, which does not occur in rats underfed for shorter periods.

The present experiments thus emphasize the fact that with advancing age, many of the different organs show a changing tendency in their growth reaction during underfeeding. The same organ (for example, the heart or alimentary canal) in young animals during the earlier periods of fasting may manifest a marked tendency toward continued growth while the increase in body weight is greatly retarded, but later may barely maintain itself, and finally perhaps even lose weight. Other organs, like the eyeballs, spinal cord and skeleton, continue to grow or maintain their weight with remarkable persistency; while still others (thymus) show a marked loss throughout all periods of inanition. These changes in weight in the various systems and organs of the young body during inanition are probably correlated with histological, chemical and physiological changes concerning which as yet but little is known.

\section{SUMMARY}

The more important results of the present investigation may be summarized briefly as follows:

Newborn albino rats are able to withstand separation from the mother for nearly one-half of the total time for the usual nursing period of three weeks, resulting in great retardation of the normal growth of the body as a whole.

During the underfeeding, the tail in the test rats elongates more rapidly than the body, thus producing relatively long-tailed individuals.

The eyelids in the test rats open at a body weight lower than in the controls, but the time of opening is somewhat delayed.

As to the body proportions, the weights of the extremities are 
but slightly (if at all) ehanged in the test rats during both short and very long fasting periods. The head apparently increases slightly in weight, especially during the very long fasts, the increase being compensated by a slight decrease in the weight of the trunk.

The results for the various systems are as follows:

The skeleton shows a considerable increase in weight in the test rats. The growth apparently proceeds along the lines of normal development, as indicated by a decrease in water-content, the appearance of third molar teeth, and by formation and fusion of various epiphyses.

The musculature in the test rats increases slightly in weight in the majority of cases.

The visceral group (as a whole) shows a considerable increase in weight in the test rats underfed from birth to three, six and ten weeks of age. During the longer fasts there is apparently a less definite change, with a tendency to decrease in the majority of cases.

The integument remains practically normal in weight in the rats underfed from birth to three weeks, but shows a marked loss in weight later. Although the integument as a whole loses weight during underfeeding to ten weeks of age, nevertheless the external ear continues to grow considerably in size, and tends to assume the normal adult appearance. The continued growth of the ear is probably associated with the persistent growth tendency of its skeletal (cartilaginous) portion.

The 'remainder' appears to decrease in the rats underfed to three weeks of age, which is partly compensated for by skeletal increase. During the longer fasts there is a slight increase in the weight of the 'remainder' in the majority of cases.

In general, therefore, in young rats subjected to prolonged inanition, there appears to be a progressive tendency in the skeleton and (to a slight extent) in the musculature to increase in weight, counterbalanced by a decrease in the integument and viscera. The individual organs of the visceral group vary greatly, however.

The brain shows a very marked increase in weight in the test 
rats underfed to three weeks, and also to a slight extent at later periods.

The spinal cord shows a marked increase in weight in the test rats up to ten weeks of age, and also to a lesser degree in the longer periods.

There is a marked increase in the weight of the eyeballs in the test rats during both the short and the very long fasts.

The thyroid gland apparently remains practically unchanged in weight in the test rats at three, six, and ten weeks, but usually suffers a loss later.

The thymus shows a progressive decrease to about 80 per cent loss in weight in the test rats at ten weeks, with still greater loss (up to 94 per cent) at later periods.

There is little change in the weight of the heart in the test rats at three weeks. At six and ten weeks there is an apparent increase of 13 and 27 per cent respectively. During the longer fasting periods the heart apparently loses weight.

At three, six and ten weeks the lungs show a loss of about 29 per cent in the test rats. At the later periods there is an apparent increase which is of questionable significance.

The liver shows an apparent increase of 16,70 and 64 per cent in weight in the test rats at three, six and ten weeks, respectively. During the very long fasts it is variable, with a tendency to decrease considerably in the majority of cases.

There is an apparent loss of 49 per cent in the weight of the spleen in the test rats at three weeks, while at six and ten weeks there is an apparent increase of about 27 per cent. During the later periods the spleen is variable, showing a tendency to decrease in most instances.

The alimentary canal, including contents, shows a loss in the test rats at three weeks of age, whereas at six and ten weeks there is an apparent increase. The changes are variable in the longer periods.

There is a marked increase in the weight of the empty alimentary canal in the test rats up to ten weeks. A reduction in weight, however, usually occurs during the very prolonged fasts.

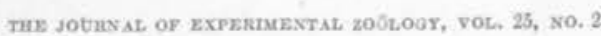


The suprarenals in the test rats show a progressive increase in weight amounting to about 114 per cent at ten weeks, which usually is maintained, to a lesser degree, during the longer fasts, in the majority of cases. At ten weeks of age and also at subsequent periods the suprarenals are heavier in the test females than in the test males of corresponding age and body weight, thus indicating the appearance of sexual differentiation in weight during underfeeding.

There is an increase in the weight of the kidneys in the test rats at three, six, and ten weeks of age, but its variation from the normal appears doubtful at later periods.

The testes show a marked increase in weight in the test rats at three, six, and ten weeks, but later are variable, in some cases showing no change, and in other instances losing considerably in weight.

There is an increase in the weight of the epididymides of 95 and 14 per cent in the test rats at three and six weeks respectively. At ten weeks and later the epididymides apparently lose weight in the underfed rats.

The ovaries show a marked increase in the test rats at three, six and ten weeks of age, but are variable later, in most instances showing a tendency to increase.

There is an increase in the weight of the hypophysis in the test, rats at three, six and ten weeks. Later the hypophysis is variable, showing a loss in the males and an increase in the females in most instances. In the very old test females the weight of the hypophysis is higher than in the corresponding males, indicating that sexual differentiation in the weight of the gland had occurred.

There is apparently no definite change in the weight of the pineal body during either short or very long periods of fasting.

In general, it therefore appears that in rats underfed from birth up to three, six and ten weeks, there is a marked increase in the weight of the spinal cord, eyeballs, liver, and stomach and intestines (empty). A less marked tendency to increase occurs in the brain (especially in the earliest period), heart (progressive increase), spleen (at six and ten weeks), intestinal contents (at six and ten weeks), suprarenals (progressive increase), kidneys, 
testes, epididymi (at three and six weeks, loss later), ovaries and hypophysis.

There is no marked change in the weights of the thyroid and pineal glands. A marked loss in weight occurs in the lungs and especially in the thymus. In the earliest period only (up to three weeks) there is a loss in the weight of the spleen and intestinal contents.

In the rats underfed for very long periods (starting at three weeks of age), the well-marked increase is maintained in the weight of the spinal cord, eyeballs, and usually of the suprarenals. The brain also shows a slight increase. In the ease of the lungs, however, the apparent increase is of doubtful significance. There is apparently no marked change (or inconstant variability) in the weights of the intestinal contents, kidneys, ovaries, testes (?), and pineal body. The thyroid, thymus, heart, liver (variable), spleen (variable), alimentary canal (empty), epididymi, and hypophysis (in males) usually suffer a loss in weight during the long underfeeding periods. 


\section{LITERATURE CITED}

Aron, Haxs 1911 Nutrition and growth. Philippine Jour. Science, vol. 6, pp. 1-51.

1914 Untersuchungen über die Beeinflussung des Wachstums durch die Ernährung. Berliner klin. Woch., J. 51, S. 972-977.

voN Bechterew, W. 1895 Ueber den Einfluss des Hungerns auf die neugeborenen Thiere, insbesondere auf das Gewicht und die Entwickelung des Gehirns. Neurol. Centralblatt, Bd. 14, S. 810-817.

BIRK, W. 1911 Unterernährung und Längenwachstum beim neugeborenen Kinde. Berl. klin. Woeh., Bd. 2, S. 1227.

BRËNING, H. 1914 Experimentelle Studien über die Entwicklung neugeborener Tiere bei längerdauernder Trennung von der säugenden Mutter und nachheriger verschiedenartiger Ernährung. Jahrb. f. Kinderheilk. Bd. 80 , S. $65-85$.

Donaldson, H. H. 1911 The effect of underfeeding on the percentage of water, on the ether-alcohol extract, and on the medullation in the central nervous system of the albino rat. Jour. Comp. Neur., vol. 21, no. 2 .

1915 The Rat. Reference Tables and Data for the Albino Rat and the Norway Rat. Memoirs of The Wistar Institute of Anatomy and Biology, No. 6.

Harms, W. 1909 Ueber den Einfluss des Hungers auf die Wirbelsäule der Tritonen. Verhandl. d. deutschen zool. Gesellschaft, 19. Versamml. S. $307-312$.

HАTAI, S. 1904 The effect of partial starvation on the brain of the white rat. Am. Jour. Physiol., vol. 12, no. 1.

1908 Preliminary note on the size and condition of the central nervous system in albino rats experimentally stunted. Jour. Comp. Neur., vol. 18 , no. 2 .

1913 On the weights of the abdominal and the thoracic viscera, the sex glands, ductless glands and the eyeballs of the albino rat (Mus norvegicus albinus) according to body-weight. Am. Jour. Anat., vol. 15 , no. 1 .

1914 On the weight of the thymus gland of the albino rat (Mus norvegicus albinus) according to age. Am. Jour. Anat., vol. 16, No. 2. 1915 The growth of the body and organs in albino rats fed with a lipoidfree ration. Anat. Rec., vol. 9, no. 1 .

Hess, A. F. 1916 Infantile Scurvy III. Its influence on growth (length and weight). Amer. Jour. Diseases of Children, vol. 12, no. 2, p. 152 .

Hoskivs, E. R. 1916 The growth of the body and organs of the albino rat as affected by feeding various ductless glands (thyroid, thymus, hypophysis and pineal). Jour. Exp. Zool., vol. 21, no. 3 .

JACKson, C. M. 1912 On the recognition of sex through external characters of the young rat. Biol. Bull,, vol. 23.

1913 Postnatal growth and variability of the body and of the various organs in the albino rat. Am. Jour. Anat., vol. 15, no. 1. 

JAckson, C. M. 1915 a Effect of acute and chronic inanition upon the relative
weights of the various organs and systems of adult albino rats. Amer. Jour. Anat., vol. 18, no. 1. Also abstracted in Proc. Amer. Assn. Anatomists. Anat. Rec., vol. 9, No. 1, p. 90.

$1915 \mathrm{~b}$ Changes in the relative weights of the various parts, systems, and organs of young albino rats held at constant body-weight by underus periods. Jour. Exp. Zoöl., vol. 19, no. 2. Also feeding for various pel. 9, abstracted in Proc. Amer. Assn. Anatomis no. 1 , p. 91 .

1917 Effects of inanition and refeeding upon the growth and structure of the hypophysis in the albino rat. Amer. Jour. Anat., vol. 21 , no. 2.

JACKson, C. M., AND Lowrey, L. G. 1912 On the relative grows (skin, skeleton, ponent parts (head, trunk and extremino rat. Anat. Rec., vol. 6, no. 12. musculature and viscera) of the albinations de poids des organes lymph-

Jolly, J., ET Levin S. 1911 a Sur les modifications de 71

oides à la suite du jeune. 1911 b Sur les modicat. T. 71.

ymusinvolution. Die akzidentelle Invo-

Jonson, A. 1909 Studien uber die Thymusin. Anat., Bd. 73, S. 390-443.

lution bei Hunger. Arch. f. mikr, An the body weight of the albino rat.

KING, H. D. 1915 Growth and variab

Anat. Rec., vol. 9, no. 10. Anat.

Lowney, L. G. 1913 The growth of the dry substance in the albino rat. Anat. Rec., vol. 7 , no. 9 .

Morgutis, S. 1911 Studies of inanition in f. Entw. d. Org., Bd. 32, H. 2. body and of the various organs of young

Stewant, C. A. 1916 Growth of the body arious periods. Biol. Bull., vol. 31, albino rats after inanition for no. $1, \mathrm{pp} .16-51$. Also Abstracted in Ans of the various parts, systems 1917 Changes in the relative weights of and organs of very young albino rats underfed Anat. Rec., vol. 11, no. 6 , Abstract in Proc. Amer. Assn. of Anatomists, Anat Capacity of animals to grow under adverse conditions.

Waters, H. J. 1908 a Capacity of an Agricultural Science.

Proc. Soc. for the Promotion of Agrition upon the animal form. Presented $1908 \mathrm{~b}$ The influence of nutrion of Agricultural Science. Watson, C. 1910 Food and
London. (In the Appendix, the results of several feeding experion., etc.)
and investigations are republished from the Jour. of Physiol. nd investigations are republis 